\title{
Synthesis, characterization and isotherm studies of new composite sorbents
}

\author{
E S ZAKARIA ${ }^{1}$, I M ALI ${ }^{1}$, M KHALIL ${ }^{1, *}$, T Y MOHAMED ${ }^{2}$ and A EL-TANTAWY ${ }^{1}$ \\ ${ }^{1}$ Atomic Energy Authority, Hot Labs Center, Cairo 13759, Egypt \\ ${ }^{2}$ Faculty of Science, Chemistry Department, Benha University, Benha 13518, Egypt
}

MS received 23 November 2015; accepted 25 April 2016

\begin{abstract}
With different methods, different molar ratios and different surfactants have been investigated to reach the optimum conditions for synthesized zirconium tungstate $(\mathrm{Zr}(\mathrm{IV}) \mathrm{W}) . \mathrm{Zr}$ (IV)W with different molar ratios of o-toluidine was synthesized to reach the optimum conditions for poly-o-toluidine zirconium tungstate (POTZr(IV)W). POTZr(IV)W with different molar ratios of tungstate was used to achieve the optimum conditions for poly-otoluidine $\mathrm{Zr}$ (IV) tungstophosphate (POTZr(IV)WP). The $\mathrm{Na}^{+}$capacity for all the prepared materials was investigated in order to determine the best ion exchanger towards the absorbed ions. The chemical and physical properties of materials were determined. Sorption isotherm studies of $\mathrm{La}^{3+}, \mathrm{Ce}^{3+}, \mathrm{Nd}^{3+}$ and $\mathrm{Sm}^{3+}$ ions were performed at different reaction temperatures and analysed by Langmuir, Freundlich, Dubinin-Raduchkivich and Temkin isotherm models. Thermodynamic parameters such as $\Delta G^{\circ}, \Delta H^{\circ}$ and $\Delta S^{\circ}$ were determined and found to be endothermic and spontaneous in nature.
\end{abstract}

Keywords. Ion exchanger; composite; synthesis; characterization; isotherm; lanthanides.

\section{Introduction}

In the last decades, the demand for rare-earth elements (REEs) was increased due to the development of many advanced technologies. So REEs have received great attention due to their importance in different applications like electronics, catalysts, used in clean energy technologies of the future such as wind turbines, electric vehicles and phosphors. REEs are produced during the uranium fission and present in the radioactive waste [1]. REE-rich sources have rare-earth oxides (REOs), such as carbonate-based bastnasite and phosphate-based monazite. Lanthanide group elements are chemically similar, so their separations are difficult. Lanthanide separation and purification are important for controlling of radioactive wastes, renewable energy technologies of the future, mining industries as well as environmental remediation and pollution control. As a result of being fission product, REEs can be used as non-active simulators to investigate the expected behaviour of the long-lived, radiotoxic minor actinides [1].

Different technologies are applied for the purpose of separation and purification, such as chemical precipitation, coagulation, sedimentation, flotation, filtration, membrane processes, electrochemical techniques, ion exchange, biological processes and chemical reactions. One of the most promising technologies widely applied for metal ions retention is ion exchange. This technique has many advantages such as the simplicity of equipment, operation and regeneration [2].

*Author for correspondence (magdykhalil7@yahoo.com)
In the early days, organic resins are introduced for remediation of waste waters that may contain toxic, radioactive or precise metal ions. These organic resins are preferably used in certain process such as water treatment due to their high ion exchange capacity (IEC), good mechanical properties, but they have limitations such as poor thermal, chemical and radioactive stability, they are able to swell and they have no selective behaviour for specific metal ions [3].

Due to the limitations of organic resins, researchers developed inorganic ion exchangers that have good chemical, thermal and radiation stability, selectivity for specific metal ions, but they have limitations like low capacity compared to organic resins and irreproducibility [4]. Most of the inorganic ion exchangers [5-7], such as lithium titanate, tin silicate, tin and titanium-ferrocyanides, etc., exhibit very low ion exchange efficiency in the high acidic media.

Many researchers take great attention to create a new class of hybrid organic-inorganic ion exchangers to combine the main advantages of each constituent [8]. These hybrid ion exchangers consist of inorganic ion exchangers and organic binding matrices. Composite ion exchangers are favourably used, as they have many advantages such as improved mechanical properties due to binding of organic polymer and its granulometric properties makes them more suitable for the application in column operations. Chemical inertness, high thermal and radiation stability, reproducibility and high selectivity make them able for direct conversion to stable crystalline phases from which radionuclides cannot be leached. This makes such materials suitable for direct disposition for the disposal of long-lived heat-producing 
radionuclides. In this study various samples of poly-otoluidine zirconium tungstophosphate (POTZr(IV)WP) with different molar ratios were prepared to obtain the most effective sample, which was used for the retention of important metal ions such as $\mathrm{La}^{3+}, \mathrm{Ce}^{3+}, \mathrm{Sm}^{3+}$ and $\mathrm{Nd}^{3+}$ from aqueous solution. POTZr(IV)WP composite material was characterized by FTIR, XRD, TG-DTA, XRF, SEM and CHN elemental analysis, chemical stability and $\mathrm{pH}$ titration curve. Effect of the resin dosage experiment was studied to determine the optimum $V / m$ used in batch experiments. Sorption isotherm studies were conducted in order to investigate the sorption mechanism controlling the sorption process of $\mathrm{La}^{3+}, \mathrm{Ce}^{3+}$, $\mathrm{Sm}^{3+}$ and $\mathrm{Nd}^{3+}$ onto POTZr(IV)WP.

\section{Material and method}

\subsection{Chemicals and reagents}

The main reagents used for the synthesis were zirconium oxychloride $\left(\mathrm{ZrOCl}_{2} \cdot 8 \mathrm{H}_{2} \mathrm{O}\right)$, N-cetyl-N,N,N, trimethyl ammonium bromide, CTAB $\left(\mathrm{C}_{19} \mathrm{H}_{42} \mathrm{BrN}\right)$, sodium dodecyl sulphate, SDS $\left(\mathrm{CH}_{3}\left(\mathrm{CH}_{2}\right)_{11} \mathrm{OSO}_{3} \mathrm{Na}\right)$, all obtained from EL NASR Pharmaceutical Chemicals Co., Egypt. Sodium dioctyl sulphosuccinate, SDSC $\left(\mathrm{C}_{20} \mathrm{H}_{37} \mathrm{NaO}_{7} \mathrm{~S}\right)$, was obtained from KAMSONS Chemicals Pvt. Ltd, India. Potassium persulphate $\left(\mathrm{K}_{2} \mathrm{~S}_{2} \mathrm{O}_{8}\right)$ was obtained from LOBA CHMIE, India. Sodium tungstate $\left(\mathrm{Na}_{2} \mathrm{WO}_{4} \cdot 2 \mathrm{H}_{2} \mathrm{O}\right)$, orthotoluidine $\left(\mathrm{C}_{14} \mathrm{H}_{18} \mathrm{Cl}_{2} \mathrm{~N}_{2}\right)$, nitric acid, acetic acid, orthophosphoric acid and hydrochloric acid were purchased from Adwic, Egypt. Neodymium (III) nitrate hexahydrate was purchased from FLUKA. Samarium (III) chloride hexahydrate was purchased from Strem Chemicals, United States. Cerium (III) nitrate hexahydrate was purchased from Merch, Germany. Lanthanum (III) chloride hexahydrate was purchased from Winlab. All other reagents and chemicals were of analytical grade purity.

\subsection{Preparation of the reagent solutions}

Various concentrations of zirconium oxychloride, sodium tungstate and ortho-phosphoric acid solutions were prepared in bi-distilled water, while the solutions of o-toluidine $(0.28 \mathrm{M})$ and potassium persulphate $(0.1 \mathrm{M})$ were prepared in $1 \mathrm{M} \mathrm{HCl}$ solution.

\subsection{Synthesis of adsorbent materials}

Various adsorbents were synthesized as poly-o-toluidine, zirconium tungstate ( $\mathrm{Zr}(\mathrm{IV}) \mathrm{W}$ ) zirconium tungstophosphate and poly-o-toluidine zirconium tungstophosphate with different methods.

2.3a Synthesis of poly-o-toluidine A polymer of o-toluidine gels was prepared by mixing an equal volume ratio of the solution of $0.1 \mathrm{M}$ potassium persulphate and $0.14 \mathrm{M}$ o-toluidine. The solution of potassium persulphate was added drop by drop in the flask containing o-toluidine with continuous stirring at the room temperature. Potassium persulphate acted as an oxidizing agent resulting in the formation of polymer gel, which was kept for $1 \mathrm{~h}$ at room temperature [9].

$2.3 \mathrm{~b}$ Synthesis of $\operatorname{Zr}(I V) W$ with hydrothermal method Hydrothermal technique was used for the preparation of zirconium tungstate. A quantity of $200 \mathrm{ml}(0.1 \mathrm{M})$ sodium tungstate solution was added drop wise to $200 \mathrm{ml}(0.1 \mathrm{M})$ zirconium oxychloride solution and $0.2 \mathrm{~g}$ CTAB with continuous stirring by magnetic stirrer at room temperature ( $25 \pm$ $1{ }^{\circ} \mathrm{C}$ ). The $\mathrm{pH}$ of the mixture was adjusted at 1.5 by adding an aqueous solution of ammonia or nitric acid with constant stirring. Then, the white coloured gel was transferred into a Teflon-lined stainless-steel autoclave $(400 \mathrm{ml})$ to carry out hydrothermal reactions at $150^{\circ} \mathrm{C}$ for $24 \mathrm{~h}$. After the autoclave was allowed to cool at room temperature naturally, the supernatant liquid was decanted and the gel was rewashed with bi-distilled water in order to remove fine adherent particles and then filtered by using a centrifugation (about 4000 $\mathrm{rpm})$. The excess acid was removed by washing with bidistilled water and the material was dried in an air oven at $60 \pm 1{ }^{\circ} \mathrm{C}$. The dried product was immersed in bi-distilled water to obtain small granules. The material was converted to $\mathrm{H}^{+}$form by treating with $0.1 \mathrm{M} \mathrm{HNO}_{3}$ for $24 \mathrm{~h}$ with occasional shaking intermittently replacing the supernatant liquid with fresh acid. The excess acid was removed after several washings with bi-distilled water and then dried at $60 \pm 1{ }^{\circ} \mathrm{C}$. Several particles size of material was obtained by sieving and kept for further usage in the batch experiments [10].

2.3c Synthesis of $\operatorname{Zr}(I V) W$ with sol-gel method Various samples of inorganic precipitate of $\mathrm{Zr}(\mathrm{IV})$ tungstate was prepared at room temperature based on using different surfactants (CTAB, SDS and SDSC). The solution of $0.1 \mathrm{M}$ sodium tungstate to a mixture of aqueous solution of $0.1 \mathrm{M}$ zirconium oxychloride and ( $0.1 \mathrm{~g}$ of CTAB, $0.5 \mathrm{~g}$ of SDS and $1 \mathrm{ml}$ of SDSC) with continuous stirring by magnetic stirrer at (25 $\pm 1{ }^{\circ} \mathrm{C}$ ). Then the $\mathrm{pH}$ of the obtained mixture was adjusted at 1.5 by adding an aqueous solution of ammonia or nitric acid with constant stirring. Zirconium tungstate was obtained as white coloured gel.

2.3d Synthesis of zirconium tungstophosphate $(\operatorname{Zr}(I V) W P)$ Zirconium tungstophosphate inorganic ion exchanger was prepared by adding a mixture containing aqueous solution of $0.1 \mathrm{M}$ sodium tungstate and $4 \mathrm{M} \mathrm{H}_{3} \mathrm{PO}_{4}$ gradually to a mixture containing aqueous solution of $0.1 \mathrm{M}$ zirconium oxychloride and $0.1 \mathrm{~g}$ of cetyl trimethyl ammonium bromide with continuous stirring by magnetic stirrer at $\left(25 \pm 1^{\circ} \mathrm{C}\right)$. The $\mathrm{pH}$ of the mixture was adjusted at 1.5 by adding an aqueous solution of ammonia or nitric acid with constant 
stirring. Then white coloured gel was obtained as zirconium tungstophosphate [11].

2.3.e Synthesis of poly-o-toluidine zirconiumtungstate $(P O T Z r(I V) W)$ Poly-o-toluidine $\mathrm{Zr}(\mathrm{IV})$ tungstate cation exchanger was prepared by sol-gel method through different mixing ways.

2.3.e1 Synthesis of POTZr(IV)W by normal method In this method, the organic polymer of o-toluidine was added to the inorganic precipitate of $\mathrm{Zr}(\mathrm{IV}) \mathrm{W}$ with constant stirring. The resultant mixture turned slowly into brownish green coloured slurries. The obtained solution $\mathrm{pH}$ was adjusted to 1.5 by ammonia solution or nitric acid. The obtained slurries were kept for $24 \mathrm{~h}$ at room temperature $25 \pm 1{ }^{\circ} \mathrm{C}$ for digestion, then as mentioned below [10].

2.3.e2 Synthesis of POTZr(IV)W by chelation method In this method the hybrid material was prepared by adding solution of $200 \mathrm{ml}(0.1 \mathrm{M})$ sodium tungstate to the mixture solution of $100 \mathrm{ml}(0.1 \mathrm{M})$ zirconium oxychloride, $0.1 \mathrm{~g} \mathrm{CTAB}$ and $50 \mathrm{ml}(0.05 \mathrm{M})$ o-toluidine, then adding $50 \mathrm{ml}(0.1 \mathrm{M}) \mathrm{K}_{2} \mathrm{~S}_{2} \mathrm{O}_{8}$. The obtained mixture solution $\mathrm{pH}$ value was adjusted to 1.5 by adding ammonia solution or nitric acid. The obtained slurries were kept for $24 \mathrm{~h}$ at room temperature $25 \pm 1^{\circ} \mathrm{C}$ for digestion, then as mentioned below.

2.3.e3 Synthesis of POTZr(IV)W by insitue method In this method the composite material was prepared by adding the mixture solution of $200 \mathrm{ml}(0.1 \mathrm{M})$ sodium tungstate and
$50 \mathrm{ml}(0.1 \mathrm{M}) \mathrm{K}_{2} \mathrm{~S}_{2} \mathrm{O}_{8}$ drop wise to the mixture solution of $50 \mathrm{ml}(0.05 \mathrm{M})$ o-toluidine and $100 \mathrm{ml}(0.1 \mathrm{M})$ zirconium oxychloride with $0.1 \mathrm{~g}$ CTAB. The resultant mixture turned slowly into brownish green coloured slurries. The obtained solution $\mathrm{pH}$ was adjusted to 1.5 by ammonia solution or nitric acid and the obtained slurries were kept for $24 \mathrm{~h}$ at room temperature $25 \pm 1^{\circ} \mathrm{C}$ for digestion. The supernatant liquid was decanted and the gel was rewashed with bi-distilled water in order to remove fine adherent particles, then filtered by using a centrifugation (about $4000 \mathrm{rpm}$ ). The excess acid was removed by washing with bi-distilled water and the material was dried in an air oven at $60 \pm 1{ }^{\circ} \mathrm{C}$. The dried product was immersed in bi-distilled water to obtain small granules. The material was converted to $\mathrm{H}^{+}$form by treating with $0.1 \mathrm{M}$ $\mathrm{HNO}_{3}$ for $24 \mathrm{~h}$ with occasional shaking intermittently replacing the supernatant liquid with fresh acid. The excess acid was removed after several washings with bi-distilled water and then dried at $60 \pm 1{ }^{\circ} \mathrm{C}$. Several particles size of material was obtained by sieving and kept for further usage in the batch experiments. In this way a number of samples of POTZr(IV)W were synthesized under variable conditions. The sodium ion exchange capacities were $0.16,0.15$ and 0.24 for the normal, chelation and insitue methods, respectively. On the basis of the highest IEC $\left(0.24\right.$ meq $\left.^{-1}\right)$, sample prepared by insitue method was selected for further preparation studies as in table 1 .

2.3.f Synthesis of poly-o-toluidine $\operatorname{Zr}(I V)$ tungstophosphate (POTZr(IV)WP) POTZr(IV)WP was synthesized with different molar ratios to obtain the best sample. A volume of $0.05,0.1,0.15$ and $0.28 \mathrm{M}$ of o-toluidine was added

Table 1. Preparation conditions of various samples of POTZr(IV)WP hybrid cation exchange materials.

\begin{tabular}{|c|c|c|c|c|c|c|c|}
\hline \multirow[b]{2}{*}{ Samples } & \multicolumn{3}{|c|}{ Mixing volume ratio (v/v) } & \multirow{2}{*}{$\begin{array}{c}\text { Mixing volume } \\
\text { ratio }(\mathrm{v} / \mathrm{v}) \text { of } 0.05 \mathrm{M} \\
\text { o-toluidine }\end{array}$} & \multirow[b]{2}{*}{ Surfactants } & \multirow{2}{*}{$\begin{array}{l}\text { Appearance } \\
\text { after drying }\end{array}$} & \multirow{2}{*}{$\begin{array}{c}\mathrm{Na}^{+} \text {ion } \\
\text { exchange capacity } \\
\left(\text { meq } \mathrm{g}^{-1}\right)\end{array}$} \\
\hline & $\mathrm{ZrOCl}_{2} \cdot 8 \mathrm{H}_{2} \mathrm{O}$ & $\mathrm{Na}_{2} \mathrm{WO}_{4} \cdot 2 \mathrm{H}_{2} \mathrm{O}$ & $\mathrm{H}_{3} \mathrm{PO}_{4}$ & & & & \\
\hline S-1 & $1(0.1 \mathrm{M})$ & $1(0.1 \mathrm{M})$ & - & - & - & White granules & 0.11 \\
\hline$S-2$ & $1(0.1 \mathrm{M})$ & $1(0.1 \mathrm{M})$ & - & - & $0.5 \mathrm{~g}$ CTAB & White granules & 0.14 \\
\hline$S-3$ & $1(0.1 \mathrm{M})$ & $1(0.1 \mathrm{M})$ & - & - & $0.5 \mathrm{~g} \mathrm{SDS}$ & White granules & 0.12 \\
\hline S-4 & $1(0.1 \mathrm{M})$ & $1(0.1 \mathrm{M})$ & - & - & $1 \mathrm{ml} \mathrm{SDSC}$ & White granules & 0.16 \\
\hline S-5 & $1(0.1 \mathrm{M})$ & $1(0.1 \mathrm{M})$ & - & - & $0.2 \mathrm{~g}$ CTAB (hydrothermal) & White granules & 0.22 \\
\hline S-6 & $1(0.1 \mathrm{M})$ & $1(0.1 \mathrm{M})$ & - & 0.5 & $0.1 \mathrm{~g}$ CTAB & Black shiny & 0.3 \\
\hline S-7 & $2(0.1 \mathrm{M})$ & $1(0.1 \mathrm{M})$ & - & 0.5 & $0.1 \mathrm{~g} \mathrm{CTAB}$ & Black shiny & 0.26 \\
\hline $\mathrm{S}-8$ & $1(0.1 \mathrm{M})$ & $2(0.1 \mathrm{M})$ & - & 0.5 & $0.1 \mathrm{~g}$ CTAB & Black shiny & 0.38 \\
\hline S-9 & $1(0.1 \mathrm{M})$ & $2(0.2 \mathrm{M})$ & - & 0.5 & $0.1 \mathrm{~g} \mathrm{CTAB}$ & Black shiny & 0.32 \\
\hline S-10 & $2(0.2 \mathrm{M})$ & $1(0.1 \mathrm{M})$ & - & 0.5 & $0.1 \mathrm{~g} \mathrm{CTAB}$ & Black shiny & 0.1 \\
\hline S-11 & $1(0.2 \mathrm{M})$ & $2(0.1 \mathrm{M})$ & - & 0.5 & $0.1 \mathrm{~g}$ CTAB & Black shiny & 0.28 \\
\hline S-12 & $1(0.1 \mathrm{M})$ & $2(0.1 \mathrm{M})$ & $0.5(1 \mathrm{M})$ & 0.5 & $0.1 \mathrm{~g}$ CТAB & Black shiny & 0.44 \\
\hline S-13 & $1(0.1 \mathrm{M})$ & $2(0.1 \mathrm{M})$ & $0.5(4 \mathrm{M})$ & 0.5 & $0.1 \mathrm{~g}$ CTAB & Black shiny & 0.8 \\
\hline S-14 & $1(0.1 \mathrm{M})$ & $2(0.1 \mathrm{M})$ & $0.5(8 \mathrm{M})$ & 0.5 & $0.1 \mathrm{~g}$ CTAB & Black shiny & 0.92 \\
\hline S-15 & $1(0.1 \mathrm{M})$ & $2(0.1 \mathrm{M})$ & $0.5(4 \mathrm{M})$ & $0.5(0.1 \mathrm{M})$ & $0.1 \mathrm{~g}$ CТАВ & Black shiny & 0.98 \\
\hline S-16 & $1(0.1 \mathrm{M})$ & $2(0.1 \mathrm{M})$ & $0.5(4 \mathrm{M})$ & $0.5(0.15 \mathrm{M})$ & $0.1 \mathrm{~g}$ CTAB & Black shiny & 1.32 \\
\hline S-17 & $1(0.1 \mathrm{M})$ & $2(0.1 \mathrm{M})$ & $0.5(4 \mathrm{M})$ & $0.5(0.28 \mathrm{M})$ & $0.1 \mathrm{~g}$ CTAB & Black shiny & 1.8 \\
\hline S-18 & $1(0.1 \mathrm{M})$ & $2(0.1 \mathrm{M})$ & $0.5(4 \mathrm{M})$ & $0.5(0.28 \mathrm{M})$ & 0.2 g CTAB & Black shiny & 1.3 \\
\hline S-19 & $1(0.1 \mathrm{M})$ & $2(0.1 \mathrm{M})$ & $0.5(4 \mathrm{M})$ & $0.5(0.28 \mathrm{M})$ & $0.3 \mathrm{~g}$ CTAB & Black shiny & 1.5 \\
\hline
\end{tabular}


to the mixture solution of $0.1 \mathrm{M} \mathrm{ZrOCl}_{2} \cdot 8 \mathrm{H}_{2} \mathrm{O}$ and $0.1 \mathrm{M}$ $\mathrm{Na}_{2} \mathrm{WO}_{4} \cdot 2 \mathrm{H}_{2} \mathrm{O}$, then the obtained slurries were washed with bi-distilled water and dried at $60^{\circ} \mathrm{C}$. Later the resulted slurries were immersed in $\mathrm{HNO}_{3}$, washed again several times, dried and kept in a desiccator for further studies.

POTZr(IV)WP cation exchanger was prepared by sol-gel insitue method. The mixture solution of $200 \mathrm{ml}(0.1 \mathrm{M})$ sodium tungstate, $50 \mathrm{ml}(0.1 \mathrm{M}) \mathrm{K}_{2} \mathrm{~S}_{2} \mathrm{O}_{8}$ and $50 \mathrm{ml}(4 \mathrm{M})$ $\mathrm{H}_{3} \mathrm{PO}_{4}$ was added drop wise to a mixture solution of $50 \mathrm{ml}$ $(0.05 \mathrm{M})$ o-toluidine and $100 \mathrm{ml}(0.1 \mathrm{M})$ zirconium oxychloride with $0.1 \mathrm{~g} \mathrm{CTAB}$ with constant stirring under the best conditions for the preparation of $\mathrm{Zr}(\mathrm{IV}) \mathrm{W}$. The resultant mixture turned slowly into brownish green coloured slurries. The resultant slurries were kept for $24 \mathrm{~h}$ at room temperature $25 \pm 1{ }^{\circ} \mathrm{C}$ for digestion. The supernatant liquid was decanted and the gel was rewashed with bi-distilled water in order to remove fine adherent particles, then filtered by using a centrifugation (about $4000 \mathrm{rpm}$ ). The excess acid was removed by washing with bi-distilled water and the material was dried in an air oven at $60 \pm 1^{\circ} \mathrm{C}$. The dried product was immersed in bi-distilled water to obtain small granules. The material was converted to $\mathrm{H}^{+}$form by treating with $0.1 \mathrm{M} \mathrm{HNO}_{3}$ for $24 \mathrm{~h}$ with occasional shaking intermittently replacing the supernatant liquid with fresh acid. The excess acid was removed after several washings with bi-distilled water and then dried at $60 \pm 1{ }^{\circ} \mathrm{C}$. Several particles size of material was obtained by sieving and kept for further usage in the batch experiments [9]. In this way a number of samples of POTZr(IV)WP were synthesized under variable conditions (table 1). On the basis of the highest IEC $\left(1.8 \mathrm{meq}^{-1}\right)$ together with physical stability and appearance of beads, sample S-17 was selected for detailed studies.

\subsection{Instruments and characterization of the prepared materials}

The Fourier transform infrared spectra were recorded using an FTIR spectrometer, using Nicolet iS10 spectrometer from Meslo, USA, in the range of $4000-400 \mathrm{~cm}^{-1}$ with 32 scans at a resolution of $2 \mathrm{~cm}^{-1}$ using $\mathrm{KBr}$ disc technique. The thermal stability of prepared compounds was ascertained by thermogravimetric analysis (TGA) and differential thermal analysis (DTA). Shimadzu DTA-TGA system of type DTATGA-60, Japan, with platinum crucible and alumina powder reference was used for the measurements of the phase changes and weight losses of the sample, respectively. Samples were heated up to a temperature of $1000^{\circ} \mathrm{C}$ in the presence of nitrogen atmosphere to avoid thermal oxidation of the powder sample with a heating rate of $20^{\circ} \mathrm{C} \mathrm{min}^{-1}$. Measurements of powder X-ray diffraction patterns were carried out using Shimadzu X-ray diffractometer, Model XD 490, Shimadzu, Japan, with a nickel filter and $\mathrm{Cu}-\mathrm{K}_{\alpha}$ radiation tube. Samples were very lightly ground and mounted on a flat sample plate at room temperature. The average crystal size of the powder was calculated from diffraction peak full-width at half-maximum (FWHM), using the Scherrer equation.
Scanning electron microscopy (SEM) was performed using a high-resolution scanning electron microscope XL30 SFEG, Phillips, the Netherlands. The metal ion concentrations were measured using UV-Visible spectrophotometer, Shimadzu, Japan, and an inductively coupled plasma atomic emission spectroscopy, ICPs-7510, Shimadzu, Japan. All the $\mathrm{pH}$ values of different solutions were measured using $\mathrm{pH}$ a glass electrode, $\mathrm{AD} / 030$, Romania, with microprocessor and have an accuracy of \pm 0.02 units. The $\mathrm{pH}$ metre scale was calibrated using two standard buffer solutions within the $\mathrm{pH}$ range of the measured solution before each experiment. The deviation in the readings was in the range of \pm 0.01 at the laboratory temperature $25 \pm 1{ }^{\circ} \mathrm{C}$. A thermostated shaker, Clifton, England, was used for ion exchange equilibrium experiments. All samples and chemicals used in this work were weighted using an analytical balance of ADAM, pw124, Germany, having maximum sensitivity of $120 \mathrm{~g}$ and accuracy $\pm 0.0001 \mathrm{~g}$.

\subsection{Sodium IEC}

The ion exchange capacities of different prepared ion exchangers were determined by acid-base titration. The weighted samples of the ion exchanger in its $\mathrm{H}^{+}$form were soaked in $50 \mathrm{ml}$ of $1 \mathrm{M} \mathrm{NaCl}$ solution for at least $12 \mathrm{~h}$ with shaking at ambient temperature to exchange protons with sodium ions. The ion exchanged solution was titrated to the phenolphthalein end point ( 2 drops of ph.ph indicator, $1 \%$ ph.ph in ethanol) with a $\mathrm{NaOH}$ solution of $0.1 \mathrm{M}$ concentration. The sodium IEC was calculated using the following equation:

$$
\operatorname{IEC}\left(\text { meq g }{ }^{-1}\right)=V_{\mathrm{NaOH}} \frac{C_{\mathrm{NaOH}}}{W_{\mathrm{d}}},
$$

where $V_{\mathrm{NaOH}}, C_{\mathrm{NaOH}}$ and $W_{\mathrm{d}}$ are the volume of $\mathrm{NaOH}$ consumed in titration, the concentration of $\mathrm{NaOH}$ solution and the weight of the dry sample, respectively.

\subsection{Chemical stability}

In order to measure the stability of composite against various media, the chemical stability of POTZr(IV)WP in various acids media $\left(\mathrm{HCl}\right.$ and $\left.\mathrm{HNO}_{3}\right)$, base $(\mathrm{NaOH})$ and organic solvent (acetic acid) was studied by batch experiments. The chemical stability of $\mathrm{Zr}$ (IV)WP was determined only in acids media $\left(\mathrm{HCl}\right.$ and $\left.\mathrm{HNO}_{3}\right)$. A quantity of $50 \mathrm{mg}$ portions of each of POTZr(IV)WP and Zr(IV)WP were contacted for $24 \mathrm{~h}$ at room temperature with $50 \mathrm{ml}$ of a particular medium with intermittently shaking. After contact, the ion exchanger was separated, then dried at $70^{\circ} \mathrm{C}$ and the weight losses (\%) were calculated.

\subsection{Effect of resin dosage}

In order to obtain the optimum batch factor $(\mathrm{V} / \mathrm{m})$ used for performing the experiments, different adsorbent masses 
$(0.025,0.033,0.05,0.1,0.2$ and $0.4 \mathrm{~g})$ of POTZr(IV)WP were conducted with $10 \mathrm{ml}$ of $50 \mathrm{mg} \mathrm{l}^{-1}$ samarium(III) chloride solution in several stoppered glass bottles and kept in the thermostatic shaker water bath at room temperature for sufficient time to obtain the equilibrium. The supernatant solutions were analysed using UV-Visible spectrophotometer and the percent uptake was calculated as follows:

$$
\% \text { Uptake }=\frac{C_{0}-C_{\mathrm{e}}}{C_{0}} \times 100,
$$

where $C_{0}$ and $C_{\mathrm{e}}$ are the initial and equilibrium concentrations of metal ion in $\mathrm{mg}^{-1}$.

\section{8 pH titration}

The $\mathrm{pH}$ titration studies were performed by Topp and Pepper method to determine the functionality behaviour of POTZr(IV)WP $[12,13]$. Each $0.05 \mathrm{~g}$ of POTZr(IV)WP composite cation exchanger in $\mathrm{H}^{+}$form were placed in each of the several glass bottles containing equimolar solution of alkali metal chlorides and their corresponding hydroxide in different volume ratios such as $\mathrm{NaCl}-\mathrm{NaOH}, \mathrm{LiCl}-$ $\mathrm{LiOH}, \mathrm{KCl}-\mathrm{KOH}$ systems. The final volume was kept at 10 $\mathrm{ml}$ to maintain the ionic strength constant with intermittent shaking. The $\mathrm{pH}$ of the solution was recorded after every $24 \mathrm{~h}$ till the equilibrium was attained. The $\mathrm{pH}$ of the solution was determined after attaining the equilibrium (which needed about 7 days) and the $\mathrm{pH}$ was plotted against the milliequivalents of $\mathrm{OH}^{-}$ions that were added.

\subsection{Sorption isotherm studies}

Sorption process of the studied metal ions $\left(\mathrm{La}^{3+}, \mathrm{Ce}^{3+}, \mathrm{Nd}^{3+}\right.$ and $\mathrm{Sm}^{3+}$ ) onto POTZr(IV)WP was carried out to investigate the adsorption mechanism and other surface properties as adsorbent affinity. Sorption experiments were performed by batch method with $50 \mathrm{mg}$ of the adsorbent material conducted with $5 \mathrm{ml}$ metal ion solutions of $\mathrm{La}, \mathrm{Ce}$ and $\mathrm{Sm}$ chlorides and $\mathrm{Nd}$ nitrate with concentration range 100-1000 $\mathrm{mg} 1^{-1}$. The $\mathrm{pH}$ of the prepared metal ion solutions were kept constant at the optimum neutral $\mathrm{pH}$. The samples were established in thermostatic shaker water bath at desired reaction temperatures $\left(25,45\right.$ and $\left.65 \pm 1^{\circ} \mathrm{C}\right)$ until they reached the equilibrium time. The supernatant solution was analysed to determine the equilibrium metal ion concentration using UVVisible spectrophotometer and the adsorption capacity was calculated from the following equation:

$$
q_{\mathrm{e}}=\left(c_{0}-c_{\mathrm{e}}\right) \frac{V}{m} \mathrm{mg} \mathrm{g}^{-1},
$$

where $q_{\mathrm{e}}$ is the amount of metal ion sorbed when equilibrium is attained $\left(\mathrm{mg} \mathrm{g}^{-1}\right), C_{0}$ and $C_{\mathrm{e}}$ are the initial and equilibrium concentrations $\left(\mathrm{mg} \mathrm{l}^{-1}\right)$ of metal ion solution, $V$ the volume of the solution (1), $m$ the weight (g) of the adsorbent.

The most common models used for studying sorption isotherm are Langmuir, Freundlich, Dubinin-Radushkivech
(D-R) and Temkin isotherm models. Langmuir model assumes that monolayer adsorptions occur at finite number of active sites, which are identical and equivalent (all sites have equal affinity for the adsorbate) with no transmigration of the adsorbate in the plane of the surface. Freundlich isotherm model is the earliest known relationship describing the non-ideal and reversible adsorption, not restricted to the formation of monolayer. This empirical model can be applied to multilayer adsorption, with non-uniform distribution of adsorption heat and affinities over the heterogeneous surface. D-R model was used to distinguish the physical and chemical adsorption of metal ions with its mean free energy, $E$, per molecule of adsorbate (for removing a molecule from its location in the sorption space to the infinity). Temkin model assumes that the heat of adsorption (function of temperature) of all molecules in the layer would decrease linearly with coverage. All molecules adsorbed into the adsorbent have a uniform distribution of binding energies.

\section{Result and discussion}

Various samples of new poly-o-toluidine-based organicinorganic fibrous-type composite ion-exchange materials were developed by incorporating poly-o-toluidine into inorganic matrices of fibrous $\mathrm{Zr}(\mathrm{IV})$ tungstophosphate. Among them, sample S-17 (table 1) possessed good yield, better sodium ion-exchange capacity and both chemical and thermal stabilities. Also, sample S-17 of POTZr(IV)WP exhibited granulometric and mechanical properties, showing a good reproducible behaviour as is evident from the fact that these materials obtained from various batches did not show any appreciable deviation in their percentage of yield and ion-exchange capacities. It was also found that the values of $\mathrm{H}^{+}$adsorption and $\mathrm{H}^{+}$liberation capacities are in close agreement. This material possessed a better $\mathrm{Na}^{+}$exchange capacity ( $\left.1.8 \mathrm{meq}^{-1}\right)$ as compared to $\mathrm{Zr}(\mathrm{IV})$ tungstate $(0.38$ meq $\left.\mathrm{g}^{-1}\right)$ and $\mathrm{Zr}(\mathrm{IV})$ tungstophosphate $\left(0.92 \mathrm{meq}^{-1}\right)$. So POTZr(IV)WP (S-17) is better than the existing ones.

The chemical stability of POTZr(IV)WP and Zr(IV)WP in the aggressive media is shown in figure $1 \mathrm{a}$ and $\mathrm{b}$. From this figure, it can be seen that POTZr(IV)WP resins have good chemical stabilities in 0.1 to $4 \mathrm{M} \mathrm{HCl}$ and 0.1 to $4 \mathrm{M} \mathrm{HNO}_{3}$ aqueous solutions. The chemical stability of POTZr(IV)WP in $\mathrm{HNO}_{3}$ was better than in $\mathrm{HCl}$. POTZr(IV)WP is fairly stable in $\mathrm{CH}_{3} \mathrm{COOH}$ and $\mathrm{NaOH}$ media. The stability of POTZr(IV)WP was less than $\mathrm{Zr}(\mathrm{IV}) \mathrm{WP}$ in both of $\mathrm{HCl}$ and $\mathrm{HNO}_{3}$. The chemical stability may be due to the presence of binding polymer, which can prevent the dissolution of heteropolyacid sols or leaching of any constituent element into the solution [14]. Chemical stability of this resin is much higher than that of the similar materials obtained on the base of POT resins. Thus, exchanger is chemically resistant to most of the solvents and can be successfully used with diverse solvents in column operation.

The $\mathrm{pH}$ titration curves for POTZr(IV)WP composite cation exchanger was obtained under equilibrium conditions 


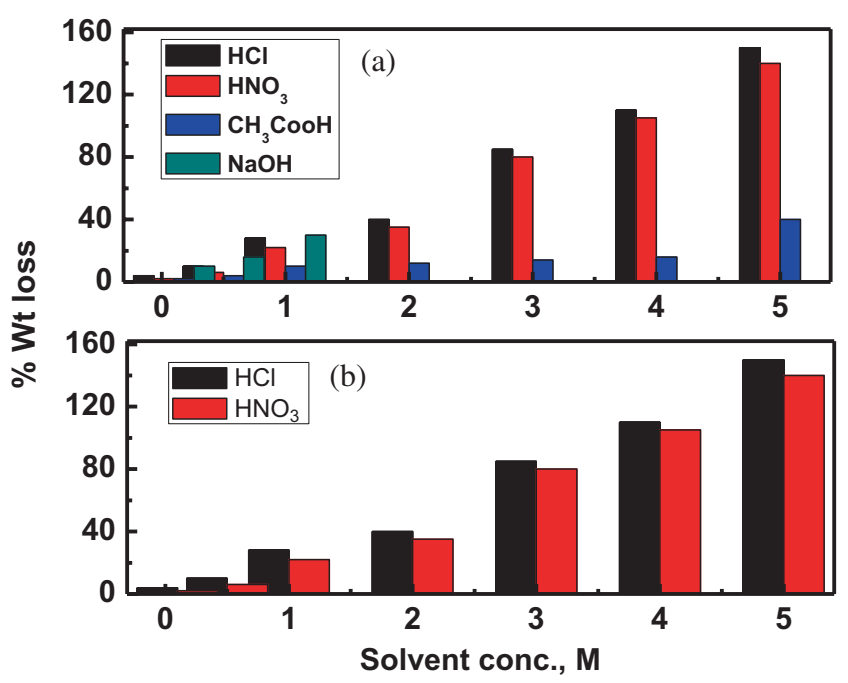

Figure 1. Chemical stability of (a) POTZr(IV)WP and (b) $\mathrm{Zr}(\mathrm{IV}) \mathrm{WP}$ in various solvents.

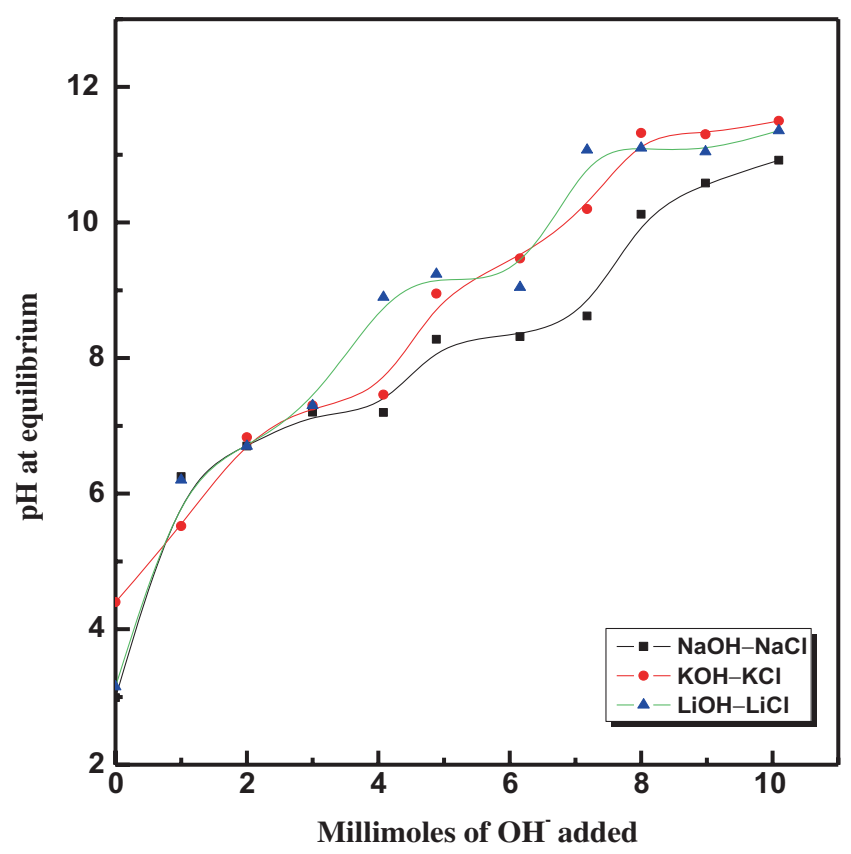

Figure 2. $\mathrm{pH}$ titration curve of $\mathrm{LiCl}-\mathrm{LiOH}, \mathrm{NaCl}-\mathrm{NaOH}$ and $\mathrm{KCl}-\mathrm{KOH}$ onto POTZr(IV)WP.

with solutions of $\mathrm{NaCl}-\mathrm{NaOH}, \mathrm{LiCl}-\mathrm{LiOH}$ and $\mathrm{KCl}-\mathrm{KOH}$ systems, which show two inflection points that indicate the bifunctional of the cation exchange behaviours (figure 2). The nano-composite materials appear to be a strong cationexchanger as indicated by a low $\mathrm{pH}(\sim 3)$ of the solutions when no $\mathrm{OH}^{-}$ions were added to the system, with further addition of $\mathrm{OH}^{-}$ions to the metal chloride solution the $\mathrm{pH}$ increases rapidly, as $\mathrm{H}^{+}$liberated from the material and replaced with alkali ions until the solution was neutralized and acidic groups of hybrid cation exchanger are completely converted into the alkali form. This means that all $\mathrm{H}^{+}$ions on the hybrid cation-exchanger were exhausted and replaced

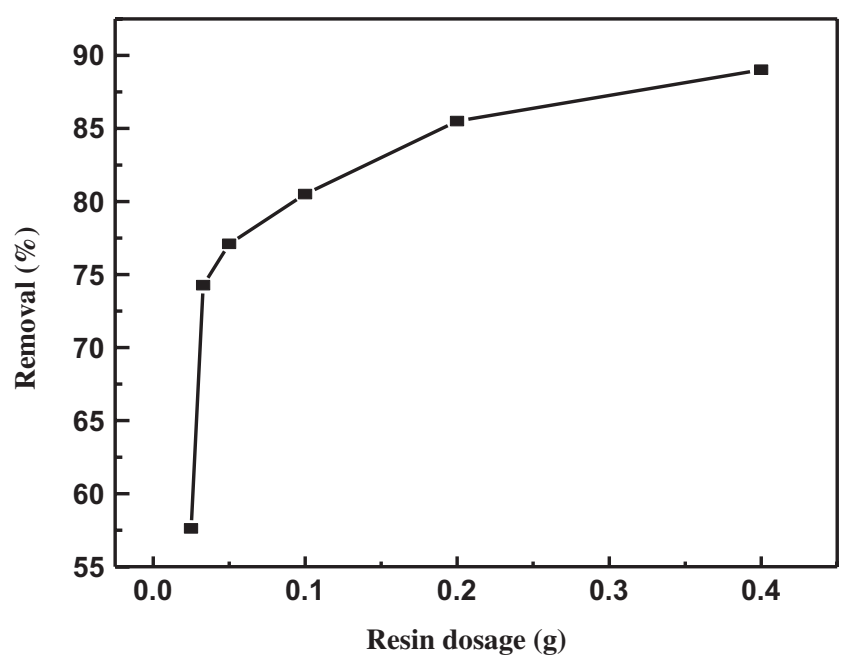

Figure 3. Effect of resin dosage on sorption of $\mathrm{Sm}(\mathrm{III})$ onto POTZr(IV)WP.

with alkali ions, and the numbers of $\mathrm{H}^{+}$liberated from the material were equivalent to the same amount of alkali interred. It is interesting to note that, $\mathrm{H}^{+}-\mathrm{Na}^{+}$exchange was faster in comparison to $\mathrm{H}^{+}-\mathrm{Li}^{+}$and $\mathrm{H}^{+}-\mathrm{K}^{+}$exchanges, as evident from lower $\mathrm{pH}$ values in case of $\mathrm{NaCl}-\mathrm{NaOH}$ system indicating higher release of $\mathrm{H}^{+}$ions [15]. Thus, the rate of exchange of $\mathrm{H}^{+}$in POTZr(IV)WP composite cation exchanger was found to be in order of $\mathrm{Na}^{+}>\mathrm{Li}^{+}>\mathrm{K}^{+}$.

The effect of POTZr(IV)WP dosage on the percent removal of $\mathrm{Sm}(\mathrm{III})$ ion is presented in figure 3. It shows that the removal percent of Sm(III) ion increased from 57.6 to 89.02 with increase in the adsorbent mass from 0.025 to $0.4 \mathrm{~g}$. This increase in the removal percent of metal ion was due to increase in the adsorbent mass; therefore, the surface area also increased indicating that more active sites are available for metal ion sorption process. It was concluded that the optimum $V / m=100$, this percent was chosen as its removal percent is high and the resin mass is low $(0.1 \mathrm{~g})$ compared with $V / m=25$, where its removal percent is slightly high and the resin mass used $(0.4 \mathrm{~g})$ was four times higher than the resin mass used to obtain $V / m=100$.

Infrared spectroscopy is a valuable tool for providing structural information and identification of unknown compounds. It is used to investigate molecular systems containing various chromospheres. The FT-IR spectra of different prepared samples are shown in figures 4-6. The FT-IR spectrum of different samples indicates the presence of extra water molecule in addition to $-\mathrm{OH}$ groups and metal oxides present in the material. A strong and broad peak around 3400 $\mathrm{cm}^{-1}$ corresponds to the presence of interstitial water and hydroxyl groups [16]. A sharp peak at $1670 \mathrm{~cm}^{-1}$ corresponds to $\mathrm{H}-\mathrm{O}-\mathrm{H}$ bending band, being also representative of the strongly bonded $-\mathrm{OH}$ groups in the matrix [17]. Peaks observed at $2920-2847 \mathrm{~cm}^{-1}$ resulted from C-H and at 1378 $\mathrm{cm}^{-1}$ due to $\mathrm{C}-\mathrm{N}$ stretching vibration band due to entering CTAB compound [18]. Spectrum also showed broad bands in the region $830-780 \mathrm{~cm}^{-1}$ and $951 \mathrm{~cm}^{-1}$ as in figure $4 \mathrm{a}$ 

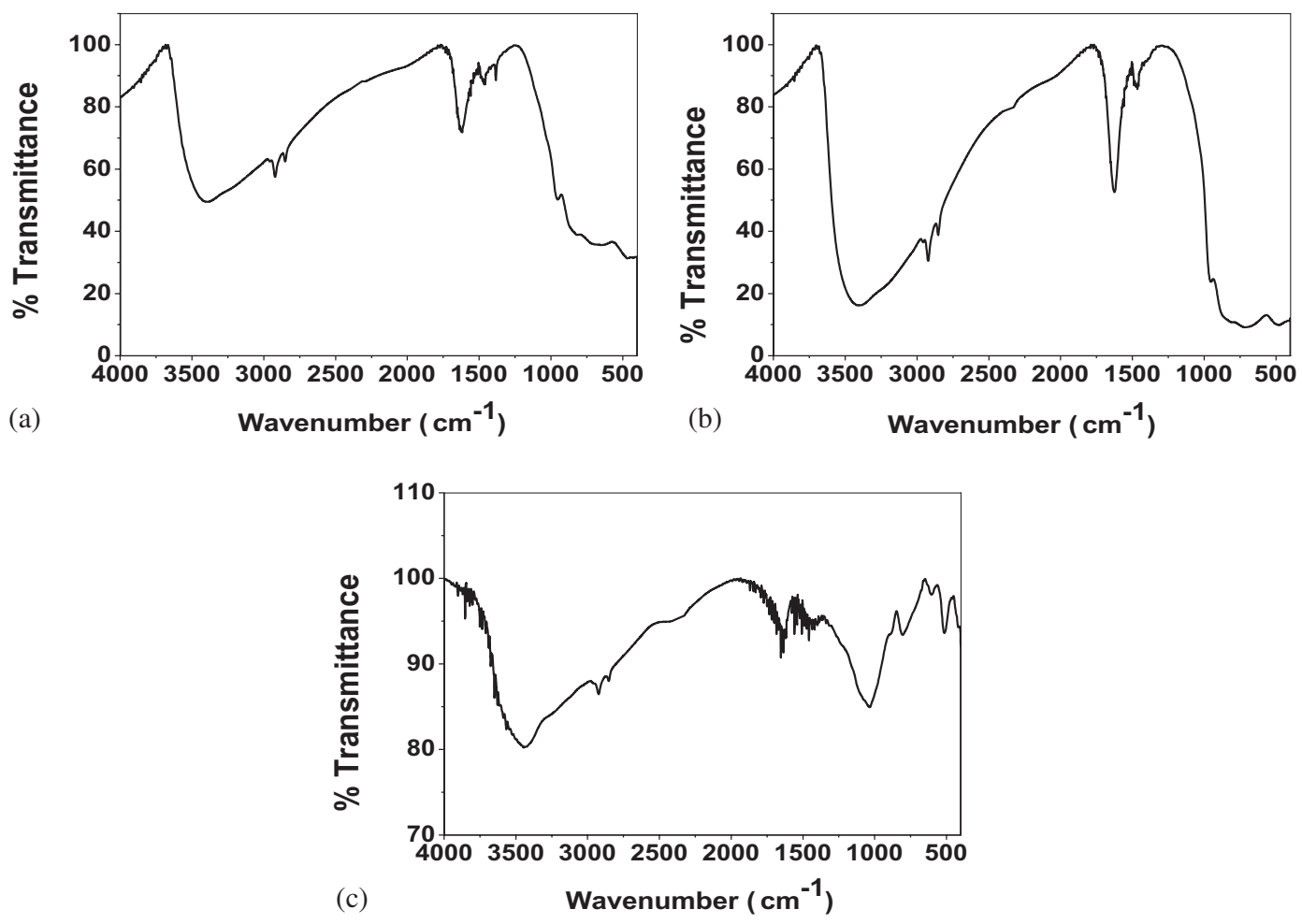

Figure 4. The IR spectra of (a) $\mathrm{Zr}(\mathrm{IV}) \mathrm{W}$, (b) $\mathrm{Zr}(\mathrm{IV}) \mathrm{W}$ hydrothermal method and (c) $\mathrm{Zr}(\mathrm{IV}) \mathrm{WP}$.

and $\mathrm{b}$, which can be assigned to the presence of $\mathrm{WO}_{4}^{2-}$ and metal-oxide groups, respectively $[19,20]$. An assembly of three peaks in the $500-800 \mathrm{~cm}^{-1}$ region may be due to the presence of $\mathrm{PO}^{3-}, \mathrm{HPO}_{4}^{2-}, \mathrm{H}_{2} \mathrm{PO}_{4}^{2-}$ as in figure $4 \mathrm{c}[21,22]$. Peaks at $1478 \mathrm{~cm}^{-1}$ and 1127 are due to $\mathrm{N}-\mathrm{H}$ bending vibration and $\mathrm{C}-\mathrm{C}$ stretching vibration band, respectively, shown in figure 5(a-c). Peaks at 1378 and $1066 \mathrm{~cm}^{-1}$ are due to $\mathrm{C}-\mathrm{N}$ and $\mathrm{C}-\mathrm{H}$ stretching vibration band of in-plane, as in figure 5c. From the IR spectra of POTZr(IV)W prepared by different methods, POTZr(IV)W prepared by insitue method was the best according to the IR spectra, so was used for latest synthesis.

Figure $6 \mathrm{a}$ and $\mathrm{b}$ shows the FT-IR spectra for POT and POTZr(IV)WP, the band at $3423 \mathrm{~cm}^{-1}$ attributed to $\mathrm{NH}_{2}$ asymmetric stretching vibrations. The band at $3220 \mathrm{~cm}^{-1}$ attributed to $\mathrm{N}-\mathrm{H}$ stretching vibration, which suggests the presence of $\mathrm{N}-\mathrm{H}$ groups in POT units as in figure 6a. The band at $2861 \mathrm{~cm}^{-1}$ is attributed to the $\mathrm{C}-\mathrm{H}$ stretching vibration of methyl group of o-toluidine, as in figure $6 a$ and b [23]. A stretching mode of $\mathrm{N}-\mathrm{H}$ unsaturated amine is represented by a band at $2337 \mathrm{~cm}^{-1}$. The skeletal vibrations of the aromatic rings show two bands at 1609 and $1481 \mathrm{~cm}^{-1}$, which are assigned to $\mathrm{C}=\mathrm{C}$ stretching vibrations of quinoid and benzoid rings, respectively, as in figure $6 \mathrm{a}$ and $\mathrm{b}$. The FT-IR spectra show that the relative intensity of benzoid ring stretching at $1481 \mathrm{~cm}^{-1}$ is higher than that of quinoid ring stretching at $1609 \mathrm{~cm}^{-1}$, as in figure 6 a. This suggests the presence of a higher fraction of benzoid rings in the synthesized POT [24]. The band at $1323 \mathrm{~cm}^{-1}$ can be attributed to $\mathrm{C}-\mathrm{N}$ stretching vibration of aromatic rings, indicating the presence of secondary aromatic amine groups, as in figure $6 \mathrm{a}$ and $\mathrm{b}$ [25]. The band at $1108 \mathrm{~cm}^{-1}$ attributes to $\mathrm{C}-\mathrm{H}$ in-plane bending) and at $806 \mathrm{~cm}^{-1}$ attributes to $\mathrm{C}-\mathrm{H}$ deformation in the methyl group attached to the phenyl ring [26]. The bands at $1029 \mathrm{~cm}^{-1}$ are due to in-plane $\mathrm{C}-\mathrm{H}$ vibration $(\gamma \mathrm{C}-\mathrm{H})$. The bands at 806 and $617 \mathrm{~cm}^{-1}$ are assigned to an out-of-plane $\mathrm{C}-\mathrm{H}$ vibration $(\gamma \mathrm{C}-\mathrm{H})$ for quinoid and benzoid rings, respectively. Figure $6 \mathrm{~b}$ shows that the FT-IR spectra of POTZr(IV)WP composites are almost identical to that of POT, indicating that o-toluidine was polymerized on the surface of $\mathrm{Zr}(\mathrm{IV}) \mathrm{WP}$ to form POTZr(IV)WP composites [27].

TGA-DTA curves, figures 7 and 8, of POTZr(IV)WP and $\mathrm{Zr}(\mathrm{IV}) \mathrm{WP}$, respectively, showed continuous mass weight loss, about $5.472 \%$ for POTZr(IV)WP and $10 \%$ for $\mathrm{Zr}$ (IV)WP, up to $200^{\circ} \mathrm{C}$, which may be due to the removal of external water molecule that supported endothermic peak of DTA curve at $95^{\circ} \mathrm{C}$ for POTZr(IV)WP and $72^{\circ} \mathrm{C}$ for $\mathrm{Zr}$ (IV)WP [28]. A slow weight loss observed between 200 and $400^{\circ} \mathrm{C}$ may be due to the condensation of phosphate group to pyrophosphate groups supported by exothermic peak at $350^{\circ} \mathrm{C}$ for POTZr(IV)WP and Zr(IV)WP [29]. A high weight loss observed between 400 and $700^{\circ} \mathrm{C}$ may be due to decomposition of organic part of the material that corresponds to the endothermic peak at $650^{\circ} \mathrm{C}$ for POTZr(IV)WP. Above $700^{\circ} \mathrm{C}$ very slight (negligible) mass weight loss observed may be due to the formation of metal oxide forms of the material. The total mass weight loss was $29.357 \%$ up to $1000^{\circ} \mathrm{C}$. Figure 5 shows TGA-DTA curve for $\mathrm{Zr}$ (IV)WP and the total weight loss was found to be $17.9 \%$ up to $800^{\circ} \mathrm{C}$. The total 


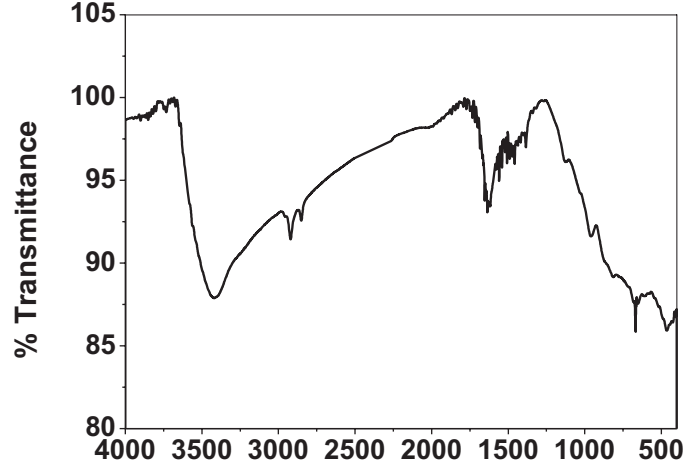

(a)
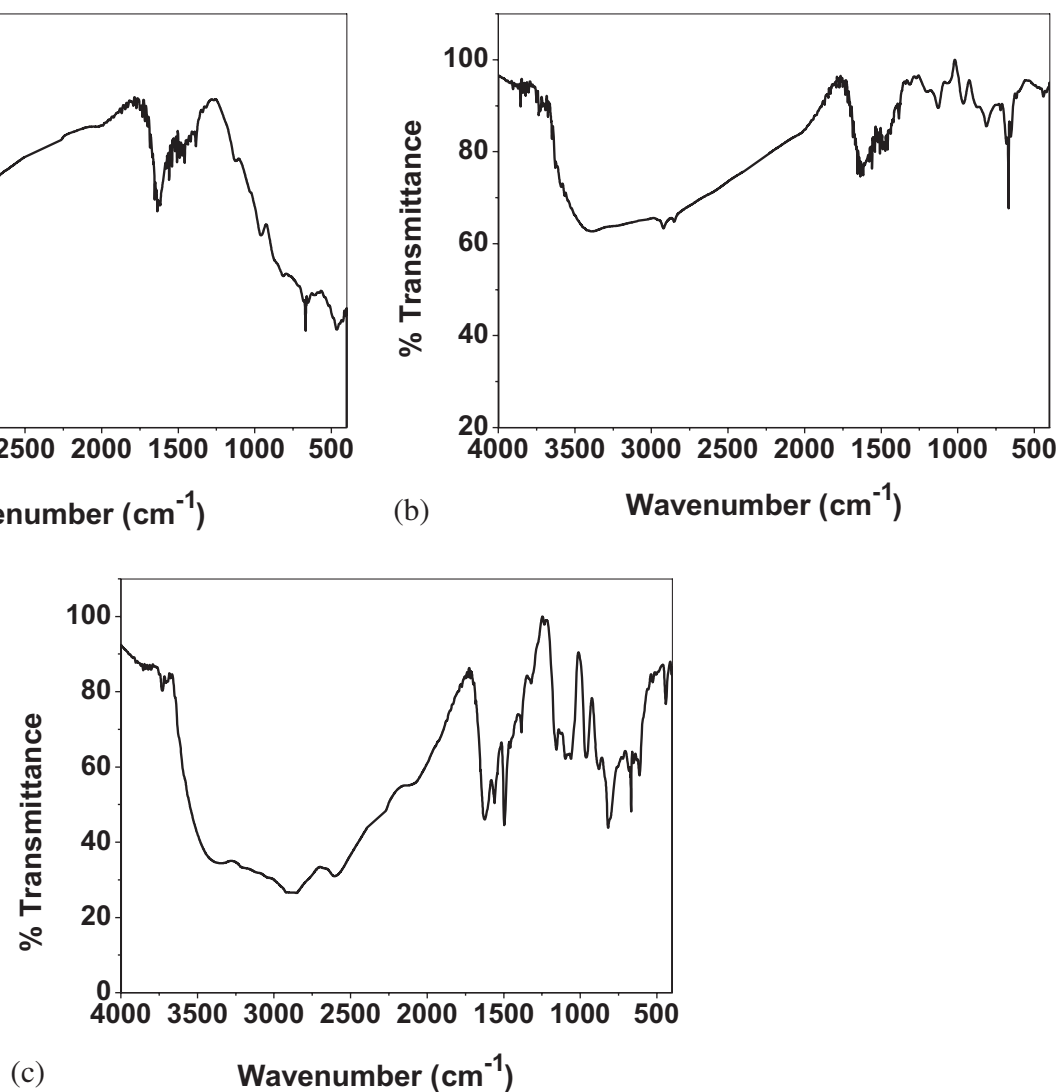

Figure 5. FT-IR spectra of POTZr(IV)W synthesized with (a) mixing, (b) insitue and (c) chelation methods.

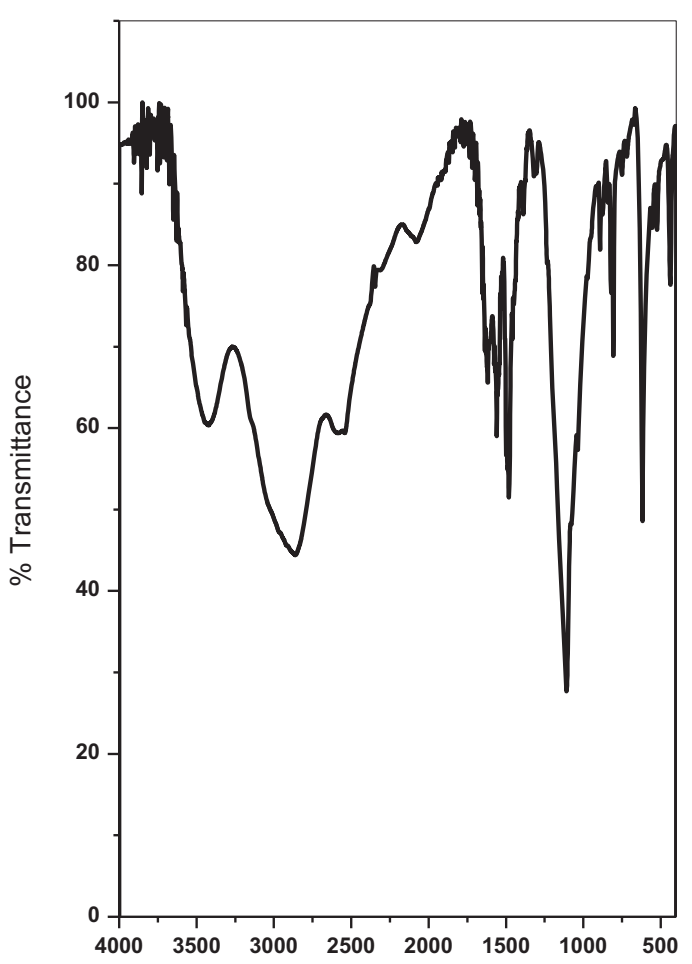

(a)

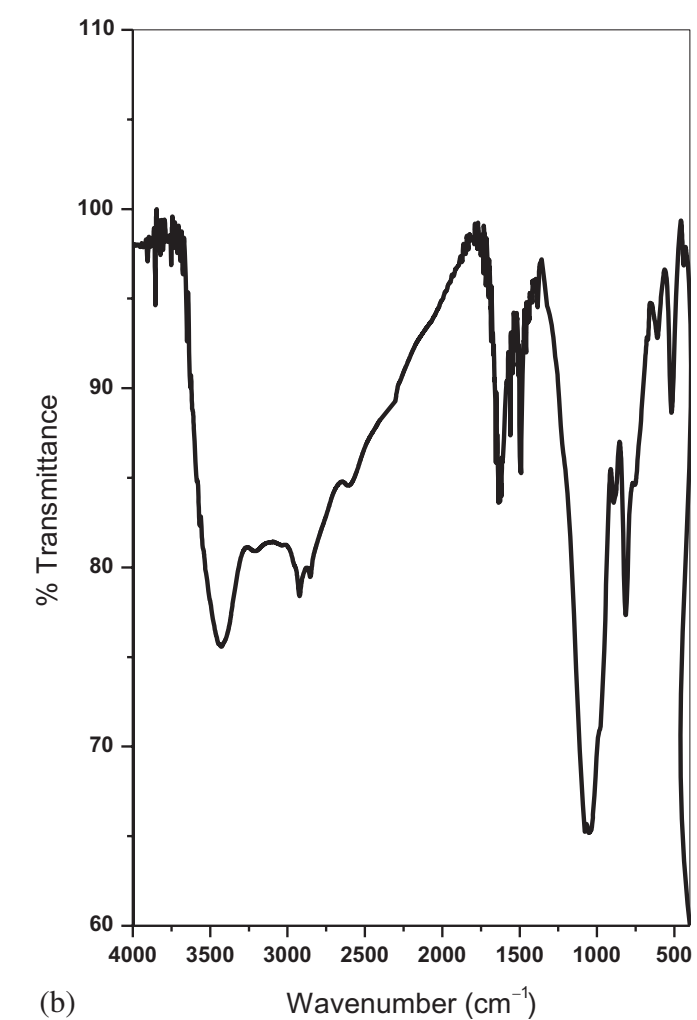

Figure 6. FT-IR spectra of (a) POT and (b) POTZr(IV)WP. 


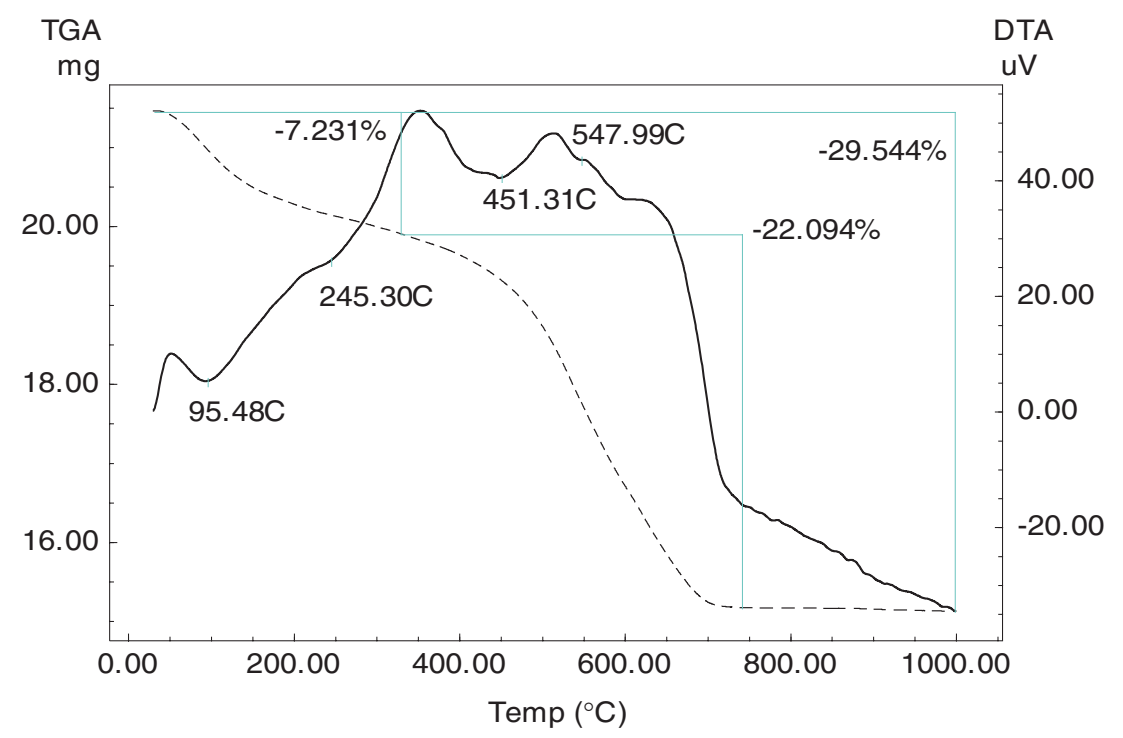

Figure 7. TGA-DTA of POTZr(IV)WP composite material.

weight loss of $\mathrm{Zr}$ (IV)WP was less than POTZr(IV)WP, as organic part in POTZr(IV)WP decomposed at $400^{\circ} \mathrm{C}$.

From the elemental composition data and elemental analysis, the weight composition percent of the material was found to be $\mathrm{Zr}, 22.13 \%$; W, $44.603 \%$; P, $7.514 \%$; C, $20.398 \%$; H, $1.956 \%$ and $\mathrm{N}, 3.398 \%$. The corresponding molar ratio of $\mathrm{Zr}$, $\mathrm{W}, \mathrm{P}, \mathrm{C}, \mathrm{H}$ and $\mathrm{N}$ was calculated as 1:1:1:7:9:1, which can suggest the following formula:

$$
\left.\left[\mathrm{ZrWO}_{4} \mathrm{H}_{2} \mathrm{PO}_{4}-\mathrm{C}_{7} \mathrm{H}_{7} \mathrm{~N}-\right)\right] \cdot n \mathrm{H}_{2} \mathrm{O}
$$

and its structure unit can be written as:

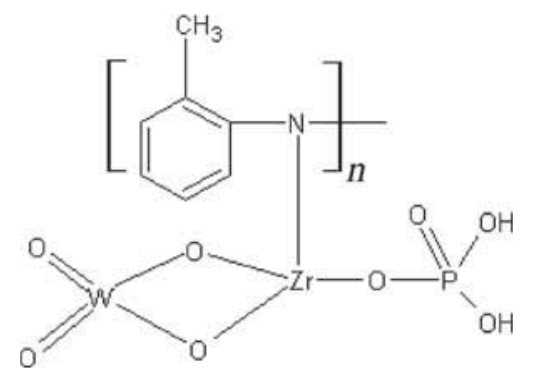

The mass weight loss was $5.47 \%$, which was lost at $200^{\circ} \mathrm{C}$ represented by TGA curve due to the loss of $n \mathrm{H}_{2} \mathrm{O}$ from the above structure. Alberti's equation was used to calculate the value of $n$ as given below [30]:

$$
18 n=\frac{X(M+18 n)}{100},
$$

where $X$ is the weight loss percent (5.472\%) of the exchanger by heating up to $200^{\circ} \mathrm{C}$ and $(\mathrm{M}+18 n)$ is the molecular weight of the material. It was found that $n=1.78$ per molecule of the cation exchanger and this crystalline water molecules can be used as active site for exchange process.

Figure 9 shows the XRD pattern of POTZr(IV)WP, indicating the semi-crystalline nature. The crystallite size, $D$, was estimated by calculating the broadening of the more intensity diffraction peak (strongest peak) according to Scherrer equation.

$$
D=K \lambda / \beta \cos \theta,
$$

where $\lambda$ is the wavelength of incident $\mathrm{X}$-ray of copper radiation source $(0.154 \pm 0.56 \mathrm{~nm}), K$ a constant depending on diffraction technique (here $K=0.89$ ), $\beta$ FWHM of Bragg peak observed at Bragg angle $\theta$ (in radian) and $\theta$ the angle of incidence of X-ray beam. It is obvious that the crystallite size of POTZr(IV)WP was $1.11 \pm 0.02 \mathrm{~nm}$.

In order to know the surface morphology of poly-otoluidine, $\mathrm{Zr}$ (IV)WP and POTZr(IV)WP composite materials SEM was used. Figure 10a-c represent the SEM photographs of poly-o-toluidine and $\mathrm{Zr}(\mathrm{IV}) \mathrm{WP}$ and POTZr(IV)WP composite materials. The composite picture was different from that of poly-o-toluidine and $\mathrm{Zr}$ (IV)WP pictures. The difference in surface morphology may be related to the formation of POTZr(IV)WP composite by binding the polymer with $\mathrm{Zr}(\mathrm{IV}) \mathrm{WP}$. According to figure 10c, it can be seen that POTZr(IV)WP was spherically shaped.

The adsorption isotherms can give the most important information about the distribution of the adsorbate molecules between the liquid and solid phases when the adsorption process reaches an equilibrium state. The surface properties and affinity of the adsorbent can be expressed by constant values of sorption isotherm models and can also be used to determine the adsorption capacities for metal ions. Various isotherm equations like those Langmuir, Freundlich, Dubinin-Radushkevich and Temkin were used to describe the equilibrium characteristics of adsorption of $\mathrm{La}^{3+}, \mathrm{Ce}^{3+}$, $\mathrm{Nd}^{3+}$ and $\mathrm{Sm}^{3+}$ ions onto POTZr(IV)WP. The accuracy of isotherm model usually related to the number of independent parameters on its equation and mathematical simplicity of any model makes it popular in the analysis of the obtained experimental data. 


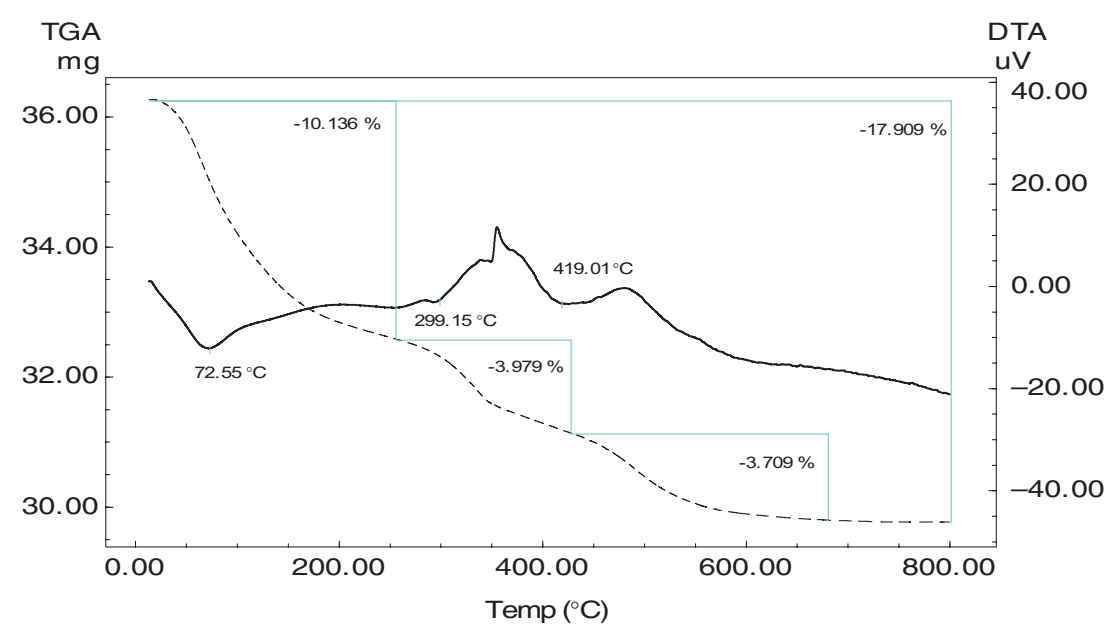

Figure 8. TGA-DTA of $\mathrm{Zr}(\mathrm{IV}) \mathrm{WP}$ inorganic adsorbent.

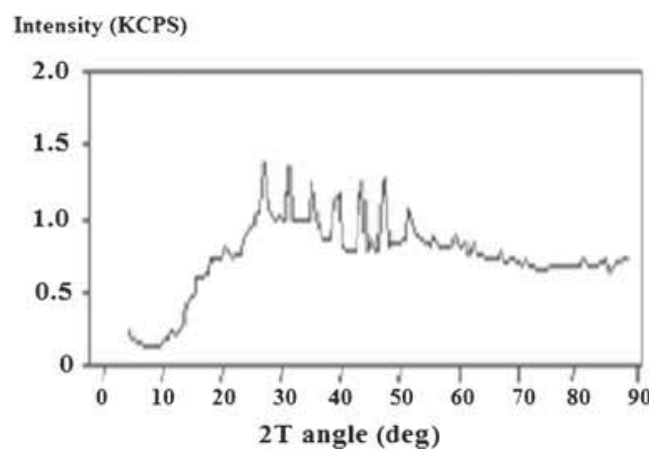

Figure 9. XRD pattern of POTZr(IV)WP composite cation exchanger.

In 1918, Langmuir has developed a theoretical equilibrium isotherm relating to the amount of gas adsorbed on a surface. Now, this model is a well-known isotherm model and widely used to quantify the performance of different adsorbents [31]. The Langmuir equation is applicable to homogeneous adsorption based on the following assumptions:

(1) Adsorption can only occur at a finite number of definite localized sites;

(2) All binding sites possess the same affinities for adsorption of a single molecular layer;

(3) There is no transmigration of the adsorbate on the plane of the surface;

(4) All sites are of equal size and shape on the surface of adsorbent.

The Langmuir equation is given as:

$$
\frac{C_{\mathrm{e}}}{q_{\mathrm{e}}}=\frac{1}{b Q_{\mathrm{o}}}+\frac{C_{\mathrm{e}}}{Q_{\mathrm{o}}},
$$

where $Q_{\mathrm{o}}$ is the maximum adsorption capacity $\left(\mathrm{mg} \mathrm{g}^{-1}\right)$ and $b$ the Langmuir constant $\left(1 \mathrm{mg}^{-1}\right)$ related to the energy of adsorption which reflects the affinity between the adsorbent and adsorbate.
A plot $C_{\mathrm{e}} / q_{\mathrm{e}} v s . C_{\mathrm{e}}$ (figure 11) yields a straight line with slope $1 / Q_{\mathrm{o}}$ and intercepts $1 / b Q_{\mathrm{o}}$. The values of Langmuir equation parameters are given in table 2 . The Langmuir model effectively and significantly described the sorption data with the $R^{2}$ values $0.992,0.989,0.996$ and 0.99 for sorption of $\mathrm{La}^{3+}, \mathrm{Ce}^{3+}, \mathrm{Nd}^{3+}$ and $\mathrm{Sm}^{3+}$ onto POTZr(IV)WP at $25^{\circ} \mathrm{C}$, respectively. According to the $Q_{\mathrm{m}}\left(\mathrm{mg} \mathrm{g}^{-1}\right)$ parameter, monolayer capacity at $25^{\circ} \mathrm{C}$ of POTZr(IV)WP was arranged in the following sequence, $\mathrm{Sm}>\mathrm{La}>\mathrm{Nd}>\mathrm{Ce}$. These metals seem to reach saturation, which means that the metal had clogged possible available sites in POTZr(IV)WP and further adsorption could take place only at new surfaces [32,33]. Also, from table 2 it is observed that an increase in the saturation capacity with increase of temperature reflects a better accessibility of the sorption sites. Based on $K_{\mathrm{L}}$ values increase in the sequence, $\mathrm{Sm}>\mathrm{La}>\mathrm{Nd}>\mathrm{Ce}$; samarium has higher affinity for POTZr(IV)WP, which is well correlated with the higher adsorption capacity $Q_{\mathrm{m}}$ obtained.

The essential characteristics and the feasibility of the Langmuir model were expressed by Weber and Chakravot in terms of a dimensionless constant, commonly known as separation factor $\left(R_{\mathrm{L}}\right)$, expressed by the following equation [34]:

$$
R_{\mathrm{L}}=\frac{1}{1+b C_{\mathrm{o}}} .
$$

The $R_{\mathrm{L}}$ values indicate either the shape of adsorption isotherm is unfavourable $\left(R_{\mathrm{L}}>1\right)$ or favourable $\left(0<R_{\mathrm{L}}<1\right)$ or linear $\left(R_{\mathrm{L}}=1\right)$ or irreversible $\left(R_{\mathrm{L}}=0\right)$.

Values of $R_{\mathrm{L}}$ calculated at 25,35 and $40^{\circ} \mathrm{C}$ for all concentrations of studied ion solutions (table 2) were in the range between 0 and 1 , which indicate that the adsorption process is favourable at operation conditions studied. For each ion, the $R_{\mathrm{L}}$ value decreases with the rise in temperature, suggesting an increase in the affinity between lanthanide ions and POTZr(IV)WP.

In 1906, Freundlich had proposed the earliest known sorption equation. It can be applied to non-ideal adsorption or 


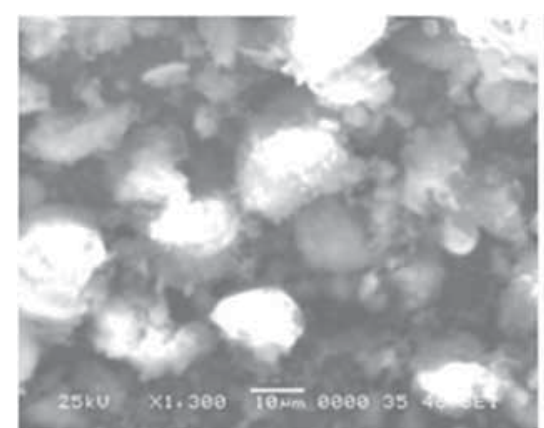

(a)

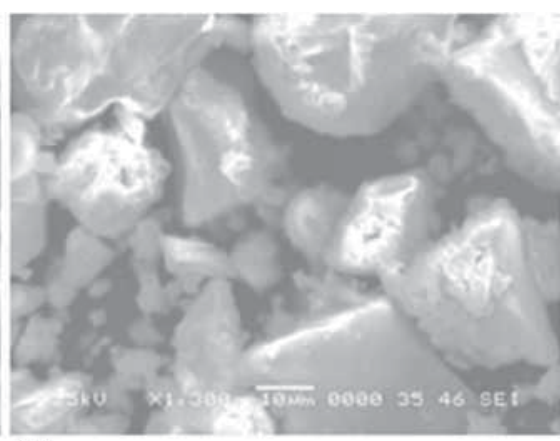

(b)

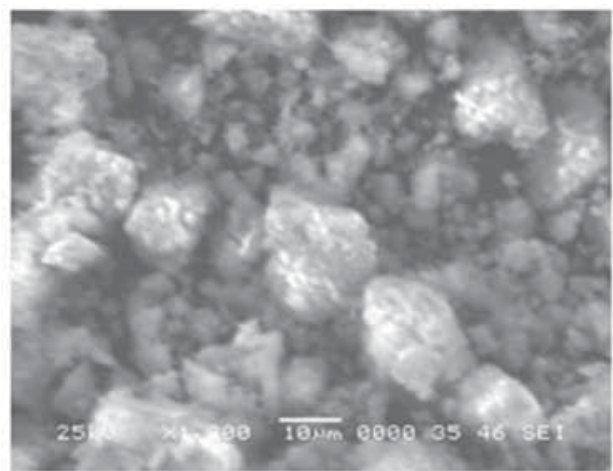

(c)

Figure 10. Scanning electron microphotograph of (a) poly-o-toluidine (POT), (b) $\mathrm{Zr}(\mathrm{IV}) \mathrm{WP}$ and (c) POTZr(IV)WP at magnification of 1,300 .
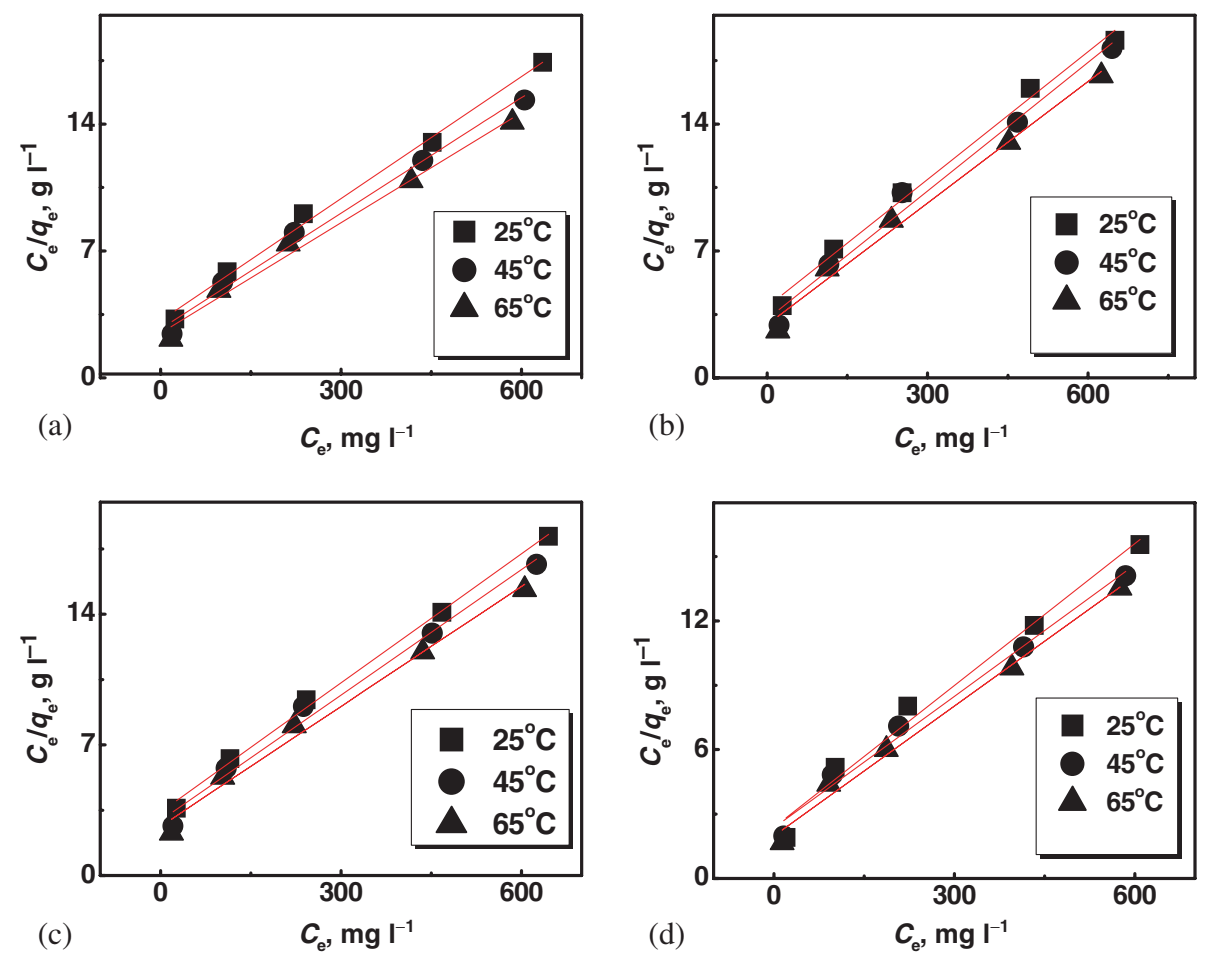

Figure 11. Langmuir isotherm model plots of (a) $\mathrm{La}^{3+}$, (b) $\mathrm{Ce}^{3+}$, (c) $\mathrm{Nd}^{3+}$ and (d) $\mathrm{Sm}^{3+}$ ion sorption onto POTZr(IV)WP at different temperatures. 
Table 2. Langmuir, Freundlich, D-R and Temkin isotherm model parameters for sorption of $\mathrm{La}^{3+}, \mathrm{Ce}^{3+}, \mathrm{Nd}^{3+}$ and $\mathrm{Sm}^{3+}$ ion onto POTZr(IV)WP composite material at different reaction temperatures.

\begin{tabular}{|c|c|c|c|c|c|c|c|c|c|c|c|c|}
\hline \multirow[b]{2}{*}{ Isotherm models } & \multicolumn{3}{|c|}{ Lanthanum } & \multicolumn{3}{|c|}{ Cerium } & \multicolumn{3}{|c|}{ Neodymium } & \multicolumn{3}{|c|}{ Samarium } \\
\hline & $25^{\circ} \mathrm{C}$ & $45^{\circ} \mathrm{C}$ & $65^{\circ} \mathrm{C}$ & $25^{\circ} \mathrm{C}$ & $45^{\circ} \mathrm{C}$ & $65^{\circ} \mathrm{C}$ & $25^{\circ} \mathrm{C}$ & $45^{\circ} \mathrm{C}$ & $65^{\circ} \mathrm{C}$ & $25^{\circ} \mathrm{C}$ & $45^{\circ} \mathrm{C}$ & $65^{\circ} \mathrm{C}$ \\
\hline \multicolumn{13}{|l|}{ Langmuir parameters } \\
\hline$Q_{\circ}\left(\mathrm{mg} \mathrm{g}^{-1}\right)$ & 44.54 & 47.01 & 49.33 & 42.61 & 42.33 & 44.72 & 43.38 & 44.66 & 46.68 & 46.93 & 48.99 & 49.58 \\
\hline$b\left(\times 10^{-3} 1 \mathrm{mg}^{-1}\right)$ & 7.12 & 7.8 & 8.20 & 6.0 & 7.33 & 7.62 & 6.77 & 7.59 & 8.13 & 7.86 & 8.65 & 10.21 \\
\hline$R_{\mathrm{L}}$ & 0.58 & 0.56 & 0.54 & 0.62 & 0.57 & 0.56 & 0.59 & 0.56 & 0.55 & 0.56 & 0.53 & 0.49 \\
\hline$R^{2}$ & 0.992 & 0.987 & 0.984 & 0.989 & 0.982 & 0.985 & 0.996 & 0.984 & 0.985 & 0.990 & 0.985 & 0.988 \\
\hline \multicolumn{13}{|l|}{ Freundlich parameters } \\
\hline $1 / n$ & 0.493 & 0.469 & 0.468 & 0.504 & 0.459 & 0.463 & 0.498 & 0.464 & 0.459 & 0.477 & 0.458 & 0.447 \\
\hline$K_{\mathrm{F}}\left(\mathrm{mg}^{\left(1-1 /{ }^{\mathrm{n}}\right)} 1^{1 / \mathrm{n}} \mathrm{g}^{-1}\right)$ & 1.68 & 2.09 & 2.25 & 1.41 & 1.94 & 2.03 & 1.55 & 2.02 & 2.22 & 1.99 & 2.39 & 2.72 \\
\hline$R^{2}$ & 0.976 & 0.989 & 0.991 & 0.981 & 0.989 & 0.991 & 0.974 & 0.99 & 0.991 & 0.983 & 0.991 & 0.983 \\
\hline \multicolumn{13}{|l|}{$D-R$ parameters } \\
\hline$Q_{\mathrm{m}}\left(\times 10^{-4} \mathrm{~mol} \mathrm{~g}^{-1}\right)$ & 7.77 & 7.68 & 8.02 & 7.28 & 6.61 & 7.07 & 7.22 & 7.42 & 6.94 & 7.45 & 7.38 & 7.53 \\
\hline$K\left(\times 10^{-3} \mathrm{~mol}^{2} \mathrm{k}^{-1} \mathrm{~J}^{-2}\right)$ & 5.73 & 4.69 & 4.00 & 5.94 & 4.65 & 4.09 & 4.00 & 5.82 & 4.62 & 4.62 & 4.46 & 3.79 \\
\hline$R^{2}$ & 0.993 & 0.992 & 0.999 & 0.995 & 0.997 & 0.998 & 0.999 & 0.992 & 0.999 & 0.997 & 0.998 & 0.993 \\
\hline$E\left(\mathrm{~kJ}^{-1} \mathrm{~mol}^{-1}\right)$ & 9.33 & 10.31 & 11.04 & 9.17 & 10.36 & 11.04 & 11.17 & 9.26 & 10.39 & 9.61 & 10.57 & 11.47 \\
\hline \multicolumn{13}{|l|}{ Temkin parameters } \\
\hline$b \times 10^{-5}\left(\mathrm{~kJ} \mathrm{~mol}^{-1}\right)$ & 6.59 & 6.66 & 6.91 & 6.25 & 5.96 & 6.27 & 6.23 & 6.10 & 6.30 & 6.25 & 6.29 & 6.33 \\
\hline$A \times 10^{3}\left(\mathrm{lg}^{-1}\right)$ & 11.64 & 13.98 & 14.26 & 9.89 & 1.20 & 1.43 & 11.04 & 13.46 & 16.03 & 14.76 & 18.20 & 21.00 \\
\hline$R^{2}$ & 0.984 & 0.975 & 0.969 & 0.984 & 0.971 & 0.970 & 0.990 & 0.970 & 0.970 & 0.980 & 0.967 & 0.965 \\
\hline
\end{tabular}

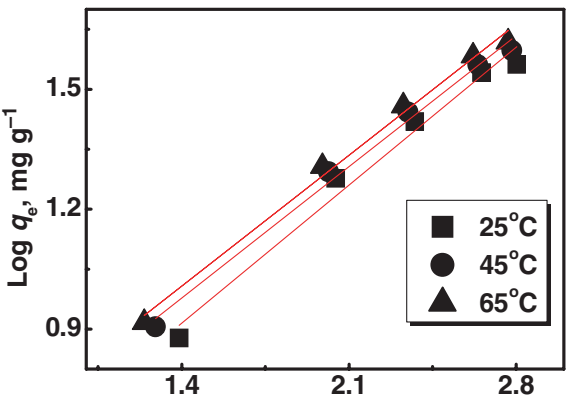

(a)

$\log C_{\mathrm{e}}, \mathrm{mg} \mathrm{l}^{-1}$

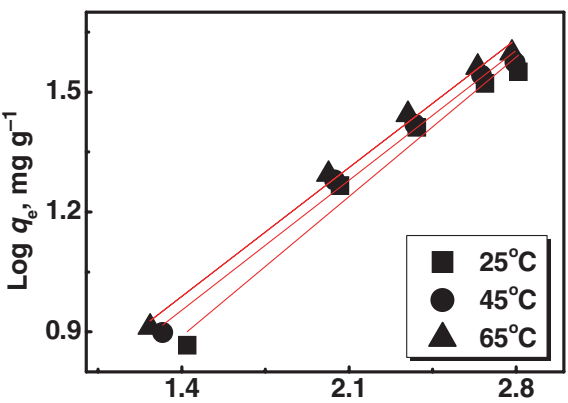

(c)

$\log C_{\mathrm{e}}, \mathrm{mg} \mathrm{I}^{-1}$

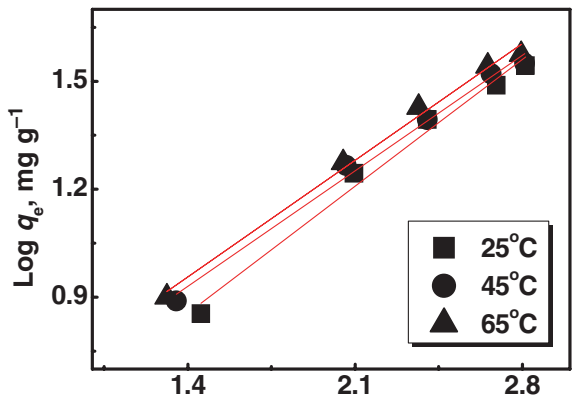

(b)

$\log C_{\mathrm{e}}, \mathrm{mg} \mathrm{I}^{-1}$

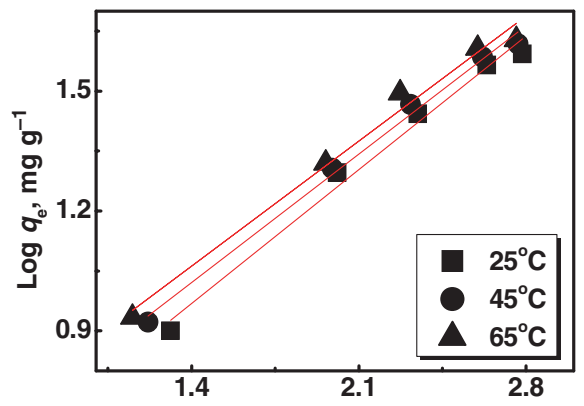

(d)

Figure 12. Freundlich isotherm model plots of (a) $\mathrm{La}^{3+}$, (b) $\mathrm{Ce}^{3+}$, (c) $\mathrm{Nd}^{3+}$ and (d) $\mathrm{Sm}^{3+}$ ion sorption onto POTZr(IV)WP at different temperatures.

multilayer sorption of adsorbate on heterogeneous surface based on the following assumptions: (1) the heat of adsorption decrease with increase in surface coverage of adsorbent and (2) the adsorption sites on the surface of adsorbent have different adsorption energies.
At present, Freundlich isotherm is widely used in different heterogeneous systems [35] and is expressed by the following equation:

$$
\log q_{\mathrm{e}}=\log K_{\mathrm{F}}+\frac{1}{n} \log C_{\mathrm{e}},
$$


where $q_{\mathrm{e}}$ is the adsorbed amount of metal ion $\left(\mathrm{mg} \mathrm{g}^{-1}\right), C_{\mathrm{e}}$ is the equilibrium concentration of metal ion $\left(\mathrm{mg} \mathrm{l}^{-1}\right), K_{\mathrm{F}}$ represents the adsorption capacity for a unit equilibrium concentration, while $1 / n$ is the indicative of the energy or intensity of the reaction and suggests the favourability and capacity of the adsorbent-adsorbate system. The values of Freundlich isotherm constants $\left(K_{\mathrm{F}}\right.$ and $\left.1 / n\right)$ determined from the linear plot of $\log q_{\mathrm{e}} v s . \log C_{\mathrm{e}}$, as in figure 12 , are presented in table 2.

Similarly to $R_{\mathrm{L}}$ values from Langmuir isotherm, the $1 / n$ value indicates the type of isotherm as follows: irreversible $(1 / n=0)$, favourable $(0<1 / n<1)$, or unfavourable $(1 / n>1)$. The Freundlich constants, $1 / n$, shown in table 2 indicate that $\mathrm{La}^{3+}, \mathrm{Ce}^{3+}, \mathrm{Nd}^{3+}$ and $\mathrm{Sm}^{3+}$ ions were adsorbed favourably by POTZr(IV)WP at all the different temperatures. The adsorption capacity $\left(K_{\mathrm{F}}\right)$ at $25^{\circ} \mathrm{C}$ of POTZr(IV)WP was arranged in the following sequence, $\mathrm{Sm}$ $>\mathrm{La}>\mathrm{Nd}>\mathrm{Ce}$ and is observed that its value increases with the increase in temperature. This sequence agreement with monolayer capacity $Q_{\mathrm{m}}$ was calculated from Langmuir isotherm. The $R^{2}$ values were $0.976,0.981,0.974$ and 0.983 for sorption of $\mathrm{La}^{3+}, \mathrm{Ce}^{3+}, \mathrm{Nd}^{3+}$ and $\mathrm{Sm}^{3+}$ onto POTZr(IV)WP at $25^{\circ} \mathrm{C}$, respectively. The $R^{2}$ Langmuir values are higher than Freundlich values. It can be seen that a good fitting of Langmuir model to experimental data is achieved. Similar behaviour was observed in adsorption process of $\mathrm{Cs}^{+}$on polyaniline titanotungstate composite cation exchanger [36].

Another equation used in the analysis of adsorption isotherms was proposed by Dubinin and Radushkevich [37]. This model was used to estimate the apparent free energy of adsorption as well as to make a difference between physical and chemical adsorption process. The D-R equation was given by the following relationship:

$$
\ln q_{\mathrm{e}}=\ln Q_{\mathrm{m}}-K \varepsilon^{2},
$$

where $Q_{\mathrm{m}}$ is the theoretical saturation capacity, $K$ the activity coefficient related to mean sorption energy and $\varepsilon$ the polanyi potential given by:

$$
\varepsilon=R_{\mathrm{g}} T \ln \left(1+\frac{1}{C_{\mathrm{e}}}\right),
$$

where $R$ is the gas constant $\left(8.314 \mathrm{~kJ} \mathrm{~mol}^{-1} \mathrm{~K}^{-1}\right)$ and $T$ the temperature $(\mathrm{K})$.

The values of isotherm constants $\left(Q_{\mathrm{m}}\right.$ and $K$ ) obtained by plotting $\ln q_{\mathrm{e}} v s . \varepsilon^{2}$, as in figure 13 , are given in table 2 . The D-R constant can give the valuable information regarding the mean energy of adsorption by the following equation:

$$
E=(-2 K)^{-0.5} \text {. }
$$

It is known that the magnitude of $E$ gives the information about the type of adsorption process: physical $(1-8 \mathrm{~kJ}$ $\mathrm{mol}^{-1}$ ), ion exchange (9-16 $\mathrm{kJ} \mathrm{mol}^{-1}$ ) and chemical $(>16 \mathrm{~kJ}$ $\mathrm{mol}^{-1}$ ) [38]. The apparent free energies of $\mathrm{La}^{3+}, \mathrm{Ce}^{3+}, \mathrm{Nd}^{3+}$ and $\mathrm{Sm}^{3+}$ adsorption on POTZr(IV)WP at different temperatures were calculated to be in the range of 9.26-11.47 $\mathrm{kJ} \mathrm{mol}^{-1}$, which means that the process is ion exchange adsorption.

Temkin and Pyzhev isotherm was proposed to describe for the first time the adsorption of hydrogen onto platinum electrodes within the acidic solution [39]. The assumptions made
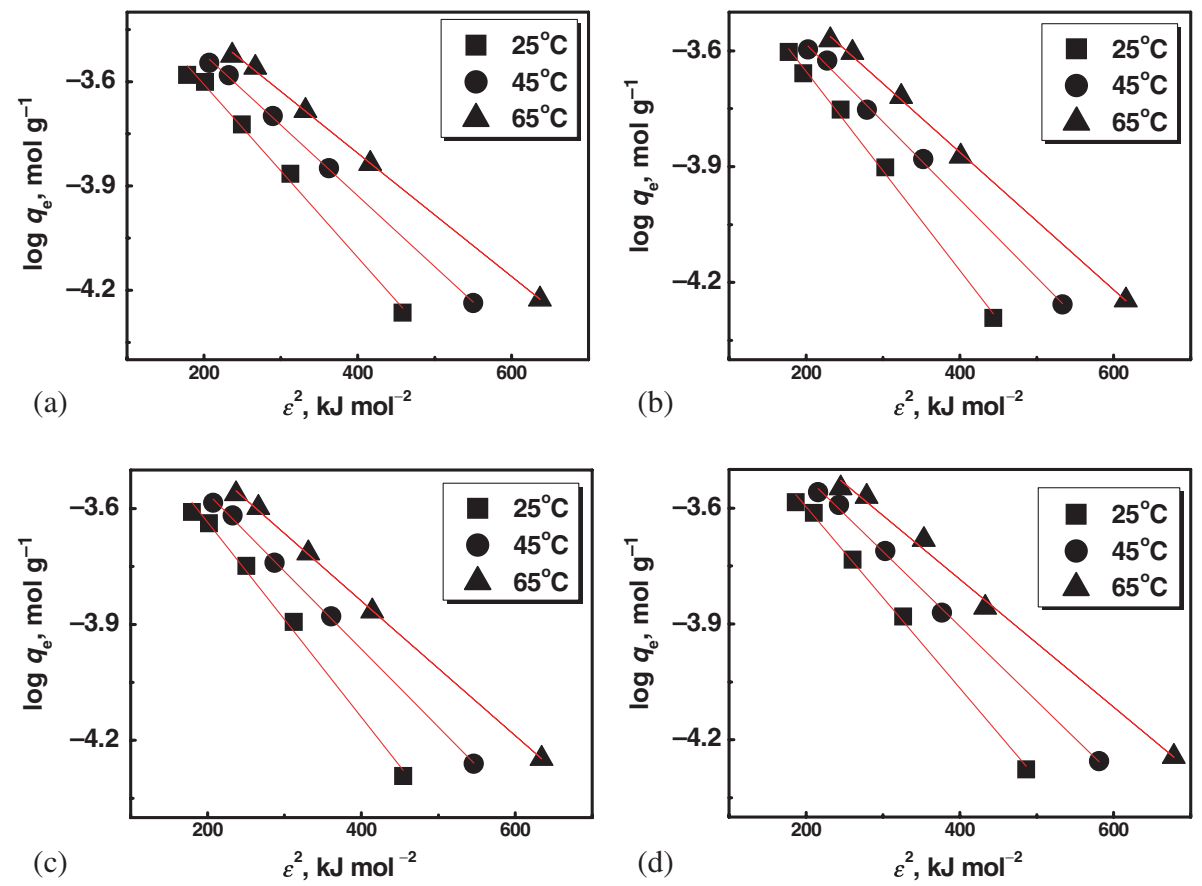

Figure 13. D-R isotherm model plots of (a) $\mathrm{La}^{3+}$, (b) $\mathrm{Ce}^{3+}$, (c) $\mathrm{Nd}^{3+}$ and (d) $\mathrm{Sm}^{3+}$ ion sorption onto POTZr(IV)WP at different temperatures. 
on the Temkin adsorption model are that: (a) adsorption is characterized by a uniform distribution of binding energies; (b) the heat of adsorption of all the molecules in the layer would decrease linearly with coverage due to adsorbentadsorbate interactions. The linear form of Temkin isotherm is given below:

$$
q_{\mathrm{e}}=b \ln A+b \ln C_{\mathrm{e}},
$$

where $b$ is the Temkin constant related to the heat of adsorption $\left(\mathrm{J} \mathrm{mol}^{-1}\right)$ and $A$ the equilibrium binding constant corresponding to the maximum binding energy $\left(1 \mathrm{mg}^{-1}\right)$.

By plotting $q_{\mathrm{e}}$ against $\ln C_{\mathrm{e}}$, as in figure 14 , we can obtain Temkin constants $A$ and $b$ as intercept and slope. The values of the Temkin parameters are given in table 3 . The Temkin constant $b$ for the adsorption of $\mathrm{La}^{3+}, \mathrm{Ce}^{3+}, \mathrm{Nd}^{3+}$ and $\mathrm{Sm}^{3+}$ on POTZr(IV)WP was $\leq 6.91 \times 10^{-5} \mathrm{~kJ} \mathrm{~mol}^{-1}$ at different temperatures. The low value of $b$ confirmed that the interaction between metal ions and the POTZr(IV)WP surface was week and ion exchange was the most suggested mechanism [40]. Based on correlation coefficient shown in table 2, the results indicate that the Langmuir and DubininRadushkevich models represent a better fit of experimental data than Freundlich and Temkin models.

The sorption amounts of single metal ions by POTZr(IV)WP are measured at temperature range 298-338 $\mathrm{K}$. The thermodynamic parameters including Gibbs free energy $\left(\Delta G^{\mathrm{o}}\right)$, enthalpy $\left(\Delta H^{\mathrm{o}}\right)$ and entropy changes $\left(\Delta S^{\mathrm{o}}\right)$ can be calculated using the following equations [41]:

$$
\Delta G^{\mathrm{o}}=-R T \ln K_{\mathrm{c}},
$$

where $R$ is the universal gas constant $\left(8.314 \mathrm{~J} \mathrm{~mol}^{-1} \mathrm{~K}^{-1}\right)$, $T$ the temperature $(\mathrm{K})$ and $K_{\mathrm{c}}$ the equilibrium constant. The $K_{\mathrm{c}}$ value was calculated using the following equation:

$$
K_{\mathrm{c}}=q_{\mathrm{e}} / C_{\mathrm{e}},
$$

where $q_{\mathrm{e}}\left(\mathrm{mg}^{-1}\right)$ and $C_{\mathrm{e}}\left(\mathrm{mg}^{-1}\right)$ are the equilibrium concentration of metal ions adsorbed onto POTZr(IV)WP and remained in the solution, respectively. The enthalpy $\left(\Delta H^{\mathrm{o}}\right)$
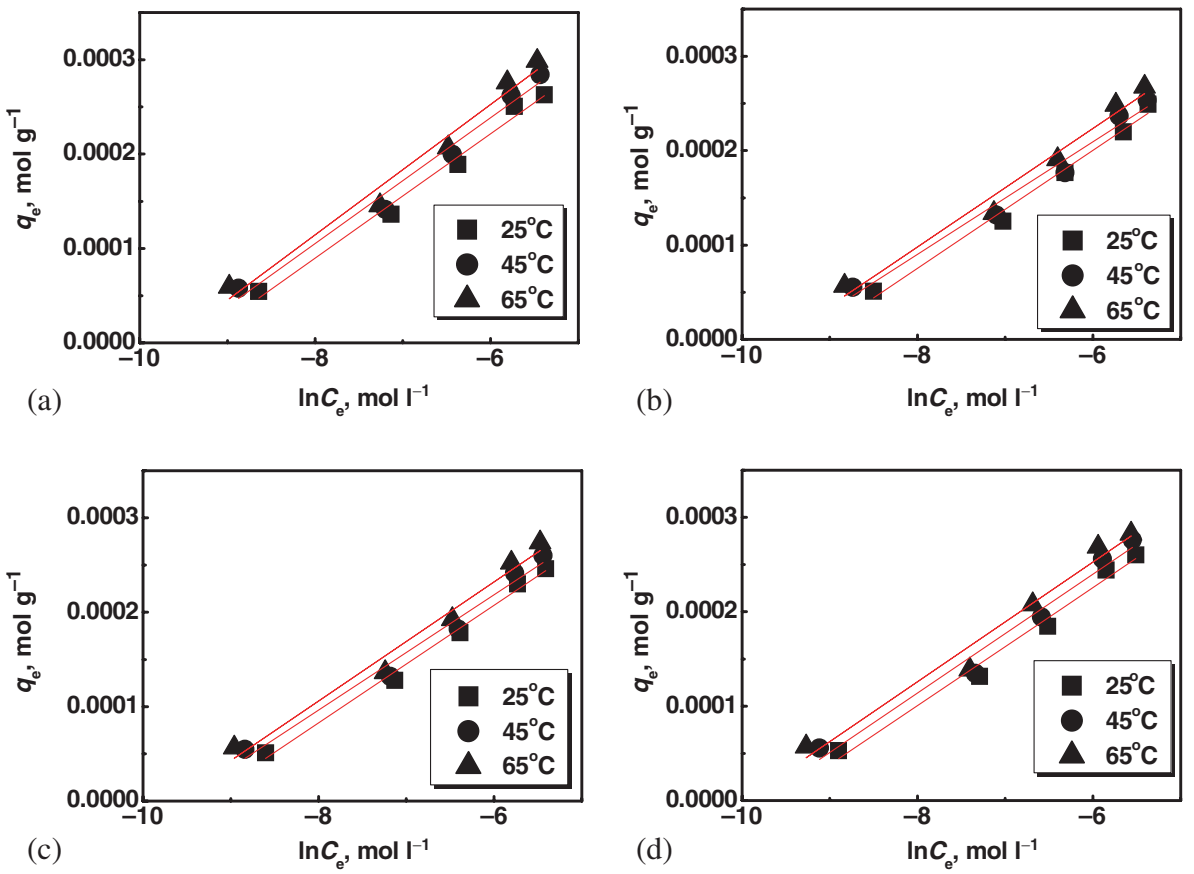

Figure 14. Temkin isotherm model plots of (a) $\mathrm{La}^{3+}$, (b) $\mathrm{Ce}^{3+},(\mathbf{c}) \mathrm{Nd}^{3+}$ and (d) $\mathrm{Sm}^{3+}$ ion sorption onto POTZr(IV)WP at different temperatures.

Table 3. Thermodynamic parameters of $\mathrm{La}^{3+}, \mathrm{Ce}^{3+}, \mathrm{Nd}^{3+}$ and $\mathrm{Sm}^{3+}$ ion sorbed onto POTZr(IV)WP.

\begin{tabular}{lccccccr}
\hline & \multicolumn{2}{c}{$\Delta G^{\circ}\left(\mathrm{kJ} \mathrm{mol}^{-1}\right)^{-1}$} & & & & \\
\cline { 2 - 4 } Metal ion & $25^{\circ} \mathrm{C}$ & $45^{\circ} \mathrm{C}$ & $65^{\circ} \mathrm{C}$ & $\Delta H^{\mathrm{o}}\left(\mathrm{kJ} \mathrm{mol}^{-1}\right) \times 10^{-3}$ & $\Delta S^{\mathrm{o}}\left(\mathrm{J} \mathrm{mol}^{-1} \mathrm{~K}^{-1}\right)$ & $R^{2}$ \\
\hline $\mathrm{La}^{3+}$ & -2.78 & -3.74 & -4.35 & 8.95 & 39.59 & 0.937 \\
$\mathrm{Ce}^{3+}$ & -2.27 & -3.26 & -3.81 & 9.19 & 38.71 & 0.904 \\
$\mathrm{Nd}^{3+}$ & -2.52 & -3.51 & -4.16 & 9.72 & 41.34 & 0.949 \\
$\mathrm{Sm}^{3+}$ & -3.35 & -4.28 & -4.94 & 9.31 & 42.59 & 0.987 \\
\hline
\end{tabular}



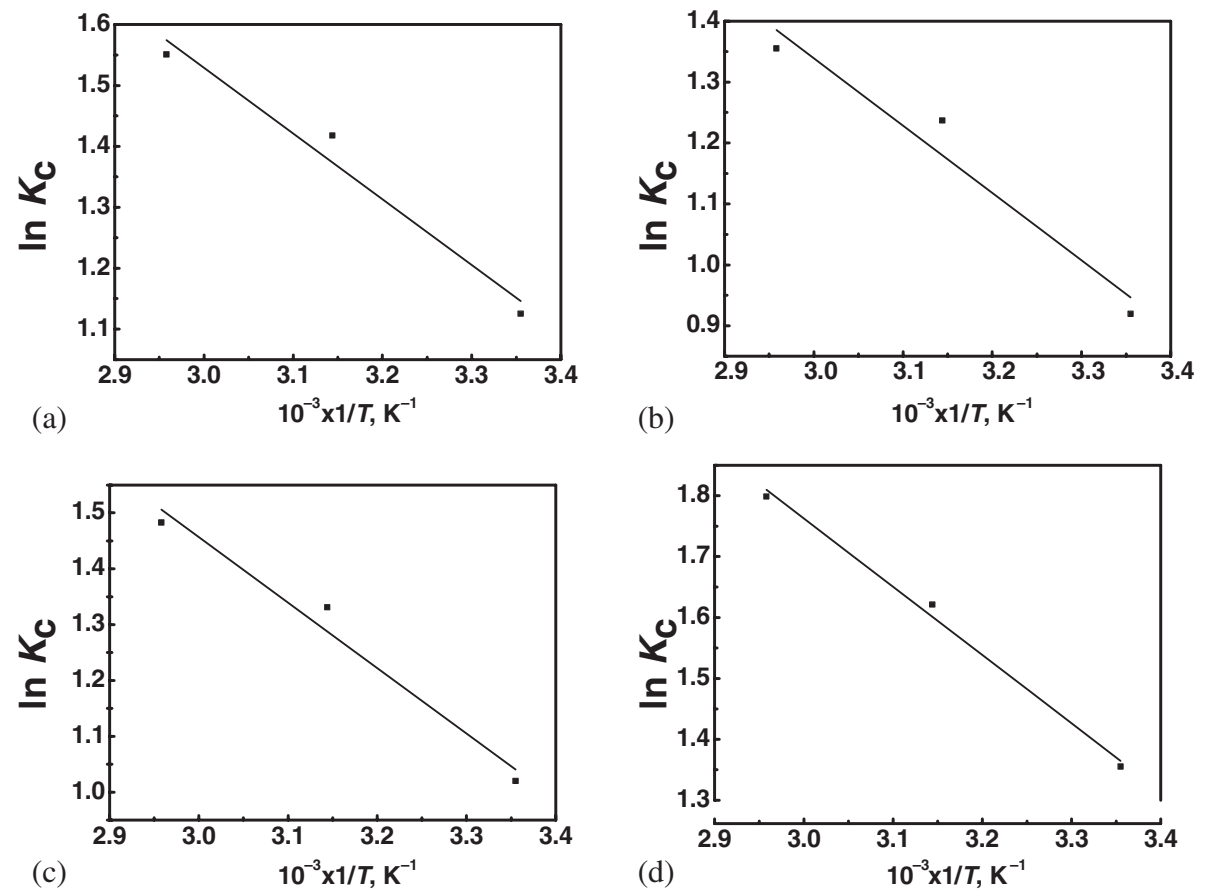

Figure 15. Plots of $\ln K_{\mathrm{c}} v s .1 / T$ for the sorption processes of (a) $\mathrm{La}^{3+}$, (b) $\mathrm{Ce}^{3+}$, (c) $\mathrm{Nd}^{3+}$ and (d) $\mathrm{Sm}^{3+}$ ion onto POTZr(IV)WP.

and entropy $\left(\Delta S^{0}\right)$ changes of adsorption were estimated from the following equation:

$$
\Delta G^{\mathrm{o}}=\Delta H^{\mathrm{o}}-T \Delta S^{\mathrm{o}} .
$$

This equation can be written as

$$
\ln K_{\mathrm{c}}=\frac{\Delta S^{\mathrm{o}}}{R}-\frac{\Delta H^{\mathrm{o}}}{R T} .
$$

According to Equation (16), the $\Delta H^{\mathrm{o}}$ and $\Delta S^{\mathrm{o}}$ were calculated from the slope and intercept of the plot between $\ln$ $K_{\mathrm{d}} v s .1 / T$, respectively, as in figure 15 and table 3 . All these relations are valid when the enthalpy change remains constant in the temperature range. The $\Delta G^{\mathrm{o}}$ values were obtained by using Equation (13) in the temperatures of 25, 45 and $65^{\circ} \mathrm{C}$. The negative values of $\Delta G^{\circ}$, for $\mathrm{La}^{3+}, \mathrm{Ce}^{3+}$, $\mathrm{Nd}^{3+}$ and $\mathrm{Sm}^{3+}$ ions, suggested the feasibility of the present adsorption process and spontaneous nature of the adsorption of $\mathrm{La}^{3+}, \mathrm{Ce}^{3+}, \mathrm{Nd}^{3+}$ and $\mathrm{Sm}^{3+}$ ions onto POTZr(IV)WP (table 3). On the other hand, the magnitude of $\Delta G^{\circ}$ increased with increase in the temperature, indicating that a better adsorption is actually obtained at higher temperatures. The positive values of $\Delta H^{\circ}$, for these ions, indicated that the endothermic nature of adsorption process was also supported by the increase in amount of metal uptake with the rise in temperature. One possible explanation of endothermic of heats of adsorption maybe due to the sorption process of metal ions onto adsorbent material requires at first solvation of these ions. For the metal ions to be adsorbed, they have to lose part of their hydration sheath and dehydration process of ions required energy so the water removing process from ions is endothermic process [42]. The positive
$\Delta S^{\mathrm{o}}$ values suggested an increase in the randomness at the solid/solution interface during the adsorption of $\mathrm{La}^{3+}, \mathrm{Ce}^{3+}$ $\mathrm{Nd}^{3+}$ and $\mathrm{Sm}^{3+}$ onto POTZr(IV)WP [43].

\section{Conclusion}

The FT-IR spectra of POTZr(IV)WP composites show that OT was polymerized on the surface of $\mathrm{Zr}(\mathrm{IV}) \mathrm{WP}$ to form POTZr(IV)WP composites. POTZr(IV)WP prepared by insitue method was the best according to the IR spectra. POTZr(IV)WP was stable in different media and at higher temperatures. XRD pattern shows that POTZr(IV)WP was in semi-crystalline nature. The formula of POTZr(IV)WP was found as $\left[\left(\mathrm{ZrO}_{2}\right)\left(\mathrm{WO}_{2}\right)\left(\mathrm{PO}_{4}\right)\left(-\mathrm{C}_{7} \mathrm{H}_{11} \mathrm{~N}-\right)\right] \cdot 1.78 \mathrm{H}_{2} \mathrm{O}$. The saturation capacity for the sorption of $\mathrm{La}^{3+}, \mathrm{Ce}^{3+}, \mathrm{Nd}^{3+}$ and $\mathrm{Sm}^{3+}$ was increased in the sequence $\mathrm{Sm}>\mathrm{La}>\mathrm{Nd}>$ $\mathrm{Ce}$; where samarium has higher affinity for $\mathrm{POTZr}(\mathrm{IV}) \mathrm{WP}$. The apparent free energies of $\mathrm{La}^{3+}, \mathrm{Ce}^{3+}, \mathrm{Nd}^{3+}$ and $\mathrm{Sm}^{3+}$ adsorption on POTZr(IV)WP at different temperatures were calculated to be in the range of $9.26-11.47 \mathrm{~kJ} \mathrm{~mol}^{-1}$, which means that the process is ion exchange adsorption. The Temkin constant $b$ for the adsorption of $\mathrm{La}^{3+}, \mathrm{Ce}^{3+}, \mathrm{Nd}^{3+}$ and $\mathrm{Sm}^{3+}$ on POTZr(IV)WP was $\leq 6.91 \times 10^{-5} \mathrm{~kJ} \mathrm{~mol}^{-1}$ at different temperatures. The low value of $b$ confirmed that the interaction between metal ions and the POTZr(IV)WP surface was weak and ion exchange was the most suggested mechanism. Correlation coefficient indicates that the Langmuir and Dubinin-Radushkevich models represent a better fit of experimental data than Freundlich and Temkin models. The negative values of $\Delta G^{\mathrm{o}}$, for $\mathrm{La}^{3+}, \mathrm{Ce}^{3+}, \mathrm{Nd}^{3+}$ 
and $\mathrm{Sm}^{3+}$ ions, suggested the feasibility of the present adsorption process and spontaneous nature of the adsorption onto POTZr(IV)WP. The positive values of $\Delta H^{\circ}$, for $\mathrm{La}^{3+}$, $\mathrm{Ce}^{3+}, \mathrm{Nd}^{3+}$ and $\mathrm{Sm}^{3+}$ ions, indicated that the endothermic nature of adsorption process was also supported by the increase in amount of metal uptake with the rise in temperature. The positive $\Delta S^{\mathrm{o}}$ values suggested an increase in the randomness at the solid/solution interface during the adsorption of $\mathrm{La}^{3+}, \mathrm{Ce}^{3+}, \mathrm{Nd}^{3+}$ and $\mathrm{Sm}^{3+}$ onto POTZr(IV)WP.

\section{References}

[1] Veliscek-Carolan J, Hanley T L and Luca V 2014 Sep. Purif. Technol. 129150

[2] Justyna J, Dorota K, Hubicki and Zbigniew 2010 Can. J. Chem. 88540

[3] Demirbas A, Pehlivan E, Gode F, Altun T and Arslan G 2005 J. Colloid. Interf. Sci. 28220

[4] Siddiqui W A, Khana S A and Inamuddin 2007 J. Colloid. Surf. A 295193

[5] El-Naggar I, Zakaria E and Ali I 2004 Sep. Purif. Technol. 394

[6] Ali I, Zakaria E and El-Naggar I 2004 Arab. J. Nucl. Sci. Technol. 3731

[7] Zakaria E, Ali I and Aly H 2004 Adsorption 1045

[8] Varshney K G, Rafiquee M Z A and Somya A 2008 Colloid. Surf. A 317400

[9] El-Naggar I M, Zakaria E S, Ali I M, Khalil M and El-Shahat M F 2012 Arab. J. Chem. 5109

[10] El-Naggar I M, Zakaria E S, Ali I M, Khalil M and El-Shahat M F 2012 J. Environ. Radioactiv. 112108

[11] El-Naggar I M, Zakaria E S, Ali I M, Khalil M and El-Shahat M F 2012 Adv. Chem. Eng. Sci. 2166

[12] Topp N E and Pepper K W 1949 J. Chem. Soc. 3299

[13] Abd El-Latif M M and Elkady M F 2011 Desalination 27141

[14] Khan A A and Inamuddin 2006 React. Funct. Polym. 661649

[15] Nabi S A, Akhtar A, Khan Md D A and Khan M A 2014 Desalination 34073

[16] Ali I 2004 J. Radioanal. Nucl. Chem. 260149

[17] Rao C N R 1963 Chemical applications of infrared spectroscopy (NY: Academic Press) p 355

[18] Rao C N R 1963 Chemical applications of infrared spectroscopy (NY: Academic Press) p 250

[19] Davis M 1963 Infrared spectroscopy and molecular structure (Amsterdam: Elsevier Publishing Co.) p 318
[20] Miller F A and Wilkins C H 1952 Anal. Chem. 241253

[21] Rao C N R 1963 Chemical applications of infrared spectroscopy (NY: Academic Press) p 353

[22] Khan A A and Akhtar T 2009 Electrochimica Acta 543320

[23] Chabukswar V S, Bhavsar and Horne A 2011 Chem. Technol. 537

[24] Kulkarni M V and Viswanath A K 2004 Eur. Polym. J. 40 379

[25] Abdiryim T, Xiao-Gang Z and Jamal R 2005 J. Appl. Polym. Sci. 961630

[26] Kulkarni M V, Viswanath A K and Mulik U P 2005 Mater. Chem. Phys. 891

[27] Fujita I, Ishiguchi M, Shiota H, Danj T and Kosai K 1992 J. Appl. Polym. Sci. 44987

[28] Ali I M, Kotp Y H and Elnaggar I M 2010 Desalination 259 228

[29] Khan A A, Inamuddin and Alam M M 2005 Mater. Res. Bull. 40289

[30] Alberti G, Torracca E and Conte A 1966 J. Inorg. Nucl. Chem. 28607

[31] Vasiliu S, Bunia I, Racovita S and Neagu V 2011 Carbohyd. Polym. 85376

[32] Ibrahim H S, Jamil T S and Hegazy E Z 2010 J. Hazard. Mater. 182842

[33] Ali I M, Zakaria E S, Ibrahim M M and El-Naggar I M 2008 Polyhedron 27429

[34] Weber T W and Chakravot R K 1974 AIChE J. 20228

[35] Freundlich H M F 1906 Z. Phys. Chem. 57385

[36] Khalil M, Chemical studies on poly aniline titanotungstate as a new composite cation exchanger and its analytical applications for removal of cesium from aqueous solution, Ain Shams University, Cairo, Egypt 2012

[37] Dubinin M M, Zaverina E D and Radushkevich L I V 1947 Russ. J. Phys. Chem. A 211351

[38] Chabani M, Amrane A and Bensmaili A 2006 Chem. Eng. J. 125111

[39] Temkin M I and Pyzhev V 1940 Acta Phys.-Chim. USSR 12 327

[40] Sheha R R and Metwally E 2007 J. Hazard. Mater. 143354

[41] Smith J M and Van Ness H C 1987 Introduction to chemical engineering thermodynamics, 4th edn (Singapore: McGrawHill)

[42] Zakaria E S, Ali I M and El-Naggar I M 2002 Colloid. Surf. A 21033

[43] Zakaria E S, Ali I M and Aly H F 2009 J. Colloid. Interf. Sci. 338346 